\title{
Prolonged activation of cytomegalovirus early gene e 1-promoter exclusively in neurons during infection of the developing cerebrum
}

Isao Kosugi ${ }^{*}{ }^{*}$,, Yoshifumi Arai ${ }^{2}$, Satoshi Baba ${ }^{3}$, Hideya Kawasaki ${ }^{4}$, Toshihide Iwashita ${ }^{1}$ and Yoshihiro Tsutsui ${ }^{1,5}$

\begin{abstract}
The brain is the major target of congenital cytomegalovirus (CMV) infection. It is possible that neuron disorder in the developing brain is a critical factor in the development of neuropsychiatric diseases in later life. Previous studies using mouse model of murine CMV (MCMV) infection demonstrated that the viral early antigen (E1 as a product of el gene) persists in the postnatal neurons of the hippocampus (HP) and cerebral cortex (CX) after the disappearance of lytic infection from non-neuronal cells in the periventricular (PV) region. Furthermore, neuron-specific activation of the MCMV-e1-promoter (e1-pro) was found in the cerebrum of transgenic mice carrying the e1-pro-lacZ reporter construct. In this study, in order to elucidate the mechanisms of e1-pro activation in cerebral neurons during actual MCMV infection, we have generated the recombinant MCMV (rMCMV) carrying long e1-pro1373- or short e1-pro448EGFP reporter constructs. The length of the former, 1373 nucleotides (nt), is similar to that of transgenic mice. rMCMVs and wild type MCMV did not significantly differed in terms of viral replication or E1 expression. rMCMV-infected mouse embryonic fibroblasts showed lytic infection and activation of both promoters, while virus-infected cerebral neurons in primary neuronal cultures demonstrated the non-lytic and persistent infection as well as the activation of e1-pro-1373, but not -448. In the rMCMV-infected postnatal cerebrum, lytic infection and the activation of both promoters were found in non-neuronal cells of the PV region until postnatal 8 days (P8), but these disappeared at P12, while the activation of e1-pro-1373, but not -448 appeared in HP and CX neurons at P8 and were prolonged exclusively in these neurons at P12, with preservation of the neuronal morphology. Therefore, e1-pro-448 is sufficient to activate E1 expression in non-neuronal cells, however, the upstream sequence from nt -449 to -1373 in e1-pro-1373 is supposed to work as an enhancer necessary for the neuron-specific activation of e1-pro, particularly around the second postnatal week. This unique activation of e1-pro in developing cerebral neurons may be an important factor in the neurodevelopmental disorders induced by congenital CMV infection.
\end{abstract}

Keywords: Cytomegalovirus, e1-promoter, Congenital infection, Persistent infection, Cerebral neuron, Neurodevelopmental disorder

\footnotetext{
*Correspondence: kos180@hama-med.ac.jp

1 Department of Regenerative \& Infectious Pathology, Hamamatsu

University School of Medicine, 1-20-1 Handayama, Higashi-Ku, Hamamatsu 431-3192, Japan

Full list of author information is available at the end of the article
}

\begin{abstract}
Introduction
Cytomegalovirus (CMV) is the leading viral cause of developmental brain disorders during the embryonic and perinatal periods in humans [14]. Microcephaly is the most prominent brain-related manifestation of congenital CMV infection [5]. Even if there are no obvious symptoms at birth, the infection occasionally persists and causes neurological disorders, including sensorineural hearing loss, mental retardation and, possibly, psychotic
\end{abstract}

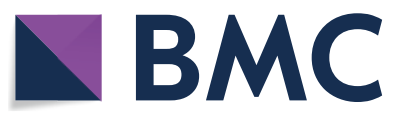

(C) The Author(s) 2021. Open Access This article is licensed under a Creative Commons Attribution 4.0 International License, which permits use, sharing, adaptation, distribution and reproduction in any medium or format, as long as you give appropriate credit to the original author(s) and the source, provide a link to the Creative Commons licence, and indicate if changes were made. The images or other third party material in this article are included in the article's Creative Commons licence, unless indicated otherwise in a credit line to the material. If material is not included in the article's Creative Commons licence and your intended use is not permitted by statutory regulation or exceeds the permitted use, you will need to obtain permission directly from the copyright holder. To view a copy of this licence, visit http://creativecommons.org/licenses/by/4.0/. The Creative Commons Public Domain Dedication waiver (http://creativeco mmons.org/publicdomain/zero/1.0/) applies to the data made available in this article, unless otherwise stated in a credit line to the data. 
diseases [15, 17, 22]. A neuron disorder in the developing brain may be a critical factor in the development of neuropsychiatric diseases in later life, although the mechanism of CMV pathogenesis in the developing brain remains poorly understood.

Although studies on human subjects, particularly in vivo studies, have obvious limitations, and while CMV has strict species specificities, animal models using murine CMV (MCMV) in place of human CMV (HCMV) have been undertaken $[49,55,59]$. MCMV shows similar characteristics to HCMV in terms of cell tropism, pathology and immunity in host-pathogen interactions [42]. Furthermore, the similarity of the MCMV genome to the HCMV genome at the genetic and nucleotide composition levels [41] and of the gene expression pattern of three sequential phases; immediate-early (IE), early (E) and late (L), have been reported [35]. In addition, as many developmental processes in mice continue to occur during the postnatal period $[16,62]$, murine neonates are useful in the investigation of the effects of infection on brain development.

The susceptibility of the brain cells and neuropathological findings are considered to be related to the developmental stages of the brain at which congenital CMV infection occurs [55]. In the early phase of brain development, neural stem/progenitor cells (NSPCs) have been reported to be the major target cells for MCMV and HCMV in the periventricular (PV) region including ventricular and subventricular zone [31, 40, 44, 51]. Most of the infected cells in this area are fully permissive for viral replication and show lytic infection, resulting in disruption of NSPC proliferation and differentiation [28, 37, 44]. During postnatal brain development in mice, a unique persistent infection occurs exclusively in the developing neurons of the hippocampus (HP) and cerebral cortex $(\mathrm{CX})$. This infection was first presented by immunostaining for the MCMV early nuclear antigen (E1) $[53,54]$. MCMV-E1 as the product of the MCMV e1 gene (M112-113) is well-known to corresponds to the product of the HCMV e1 gene (UL112-113) [10, 63]. In the developing brains of newborn mice infected with MCMV, the expression of the E1 antigen first appears in immature neural cells and non-neural cells in the PV region, and thereafter the expression of E1 disappears from the PV region but is retained exclusively in neurons of the HP and CX then up to 1 month after birth $[29,52]$.

Previously we generated transgenic mice carrying the $e 1$-promoter (e1-pro) connected with reporter gene lacZ [3]. These transgenic mice demonstrated neuronspecific activation of e1-pro, particularly after birth, suggesting that a differential transcriptional regulation of $e 1$ gene in neurons may support the neuron-specific infectious dynamics and which appears to be related with the neurological disorders induced by CMV. However, MCMV-E1 [33, 46], as well as HCMV-E1 $[1,47]$, is essential for viral DNA replication and transcriptional regulation, and is expressed in all cells permissive for viral infection. Previous studies concerning the transcriptional regulation of el gene, focused on the e1-pro sequence spanning the region from the transcriptional start site up to 300 nucleotides (nt) $[4,39,47]$. Furthermore, those experiments were performed using fibroblasts or nonneuronal cell lines. On the contrary, we have focused on the long e1-pro sequence of $\sim$ nt 1400 and our transgenic mice demonstrated the differential transcriptional activation of e1-pro in developing cerebral neurons, the activation of which was enhanced by MCMV infection. Nevertheless, there are fundamental differences in terms of $e 1$-pro activation between transgenic mice and actual MCMV infection as the e1-pro sequence exists on the host genome in the former but on the viral genome in the latter. Thus, further investigation is needed to determine whether the long e1-pro on the viral genome is similarly activated during actual CMV infection of the developing neurons as in the transgenic mice. Furthermore, the differences in the mechanisms of e1-pro activation between neurons and non-neuronal cells still remains to be clarified.

In this study, in order to investigate the spaciotemporal activation of e1-pro on the viral genome, we have constructed the recombinant MCMV (rMCMV) expressing EGFP as a reporter under the control of the long (nt 1373) or truncated short (nt 448) e1-pro fragment, rMCMV1373 or rMCMV448, respectively. We then performed in situ detection of e1-pro activity during rMCMV infection of primary neuronal cultures and neonatal mouse brains. Infection with rMCMV1373 demonstrated neuron-specific activation of MCMV e1-pro in both primary neuronal cultures and cerebral neurons, particularly around in the second postnatal week. However, infection with rMCMV448 did not show the neuronal activation of MCMV e1-pro in either model. Our results indicated that the upstream region from nt -449 to -1373 in the long e1-pro sequence is necessary for prolonged e1-pro activation in the developing cerebral neurons.

\section{Materials and methods \\ Mice}

Inbred specific pathogen-free pregnant ICR mice were obtained from SLC Japan (Hamamatsu, Japan). Newborn mice were maintained by maternal suckling during the postnatal period. All experimental procedures were performed in accordance with "Fundamental Guidelines for Proper Conduct of Animal Experiment and Related Activities in Academic Research Institutions under the 
jurisdiction of the Ministry of Education, Culture, Sports, Science and Technology (Ministry of Education, Culture, Sports, Science and Technology, Notice No. 71, 2006)" and "Guidelines for Proper Conduct of Animal Experiments (The Guide; Science Council of Japan, 2006)", and were approved by the Animal Care Committee of Hamamatsu University School of Medicine (\#2011057). Viral inoculation and sacrifice were performed under anesthesia, and all efforts were made to minimize suffering.

\section{Virus and plaque assay}

The Smith strain of wild type MCMV, which had been passaged in mouse embryonic fibroblasts (MEFs), was provided by Dr. Y. Minamishima (Miyazaki, Japan, [21]). MEFs were prepared from 12.5-day-old embryos of $\mathrm{BALB} / \mathrm{c}$ mice (SLC Japan), and were grown in Dulbecco's modified Eagle's essential medium (DMEM; SigmaAldrich, Merck, \#D5796, Darmstadt, German) containing penicillin (100 units $/ \mathrm{ml})$, streptomycin $(50 \mu \mathrm{g} / \mathrm{ml})$, and $10 \%$ fetal bovine serum (FBS; Gibco, Thermo Fisher Scientific, \#26140079, Waltham, MA). The viral titer was determined by a plaque assay in MEF monolayers as described previously [61].

\section{Recombinant viruses}

Recombinant viruses (rMCMV1373 and rMCMV448) derived from the Smith strain of wild type MCMV
(Gene accession number U68299) capable of expressing enhanced green fluorescent protein (EGFP; Gene accession number U55763, Clontech, Takara Bio USA, Mountain View, CA) as a reporter were used in this study (Fig. 1). Both viruses were constructed to express an EGFP gene insert under control of the MCMV e1-pro fragment. The e1-pro fragment of rMCMV1373 or rMCMV448 was derived from a DNA sequence from the transcription start site (position 162978) to nt -1373 (position 161605) or to nt -448 (position 162530), respectively. An e1-pro-EGFP cassette, which consisted of the e1-pro fragment including a sequence from nt -1373 or -448 to +38 relative to the transcription start site, EGFP gene and SV40-derived polyadenylation signal, was inserted into the position between 184431 and 187158 in wild type MCMV genome by homologous recombination. According to the method for the construction of rMCMV-MC.55 as reported by Dr. Mocarski's laboratory [58], we determined the insertion site of our rMCMVs as the same site as rMCMV-MC.55. This recombination causes the deletion of the nt 2728 sequence including the greater part (exon 1, exon 2 and most of exon 3) of the MCMV M128 gene (position from 186085 to 187296). However, M128 gene is completely dispensable for viral growth in cell culture as well as for growth, latency, and pathogenesis in mice [11]. It is supposed that the deletion of the M128 gene has almost no effect on endogenous ie

\section{Original e1-pro \& M112/113(e1) gene}

(position 161605-162977 / 162978-165076)

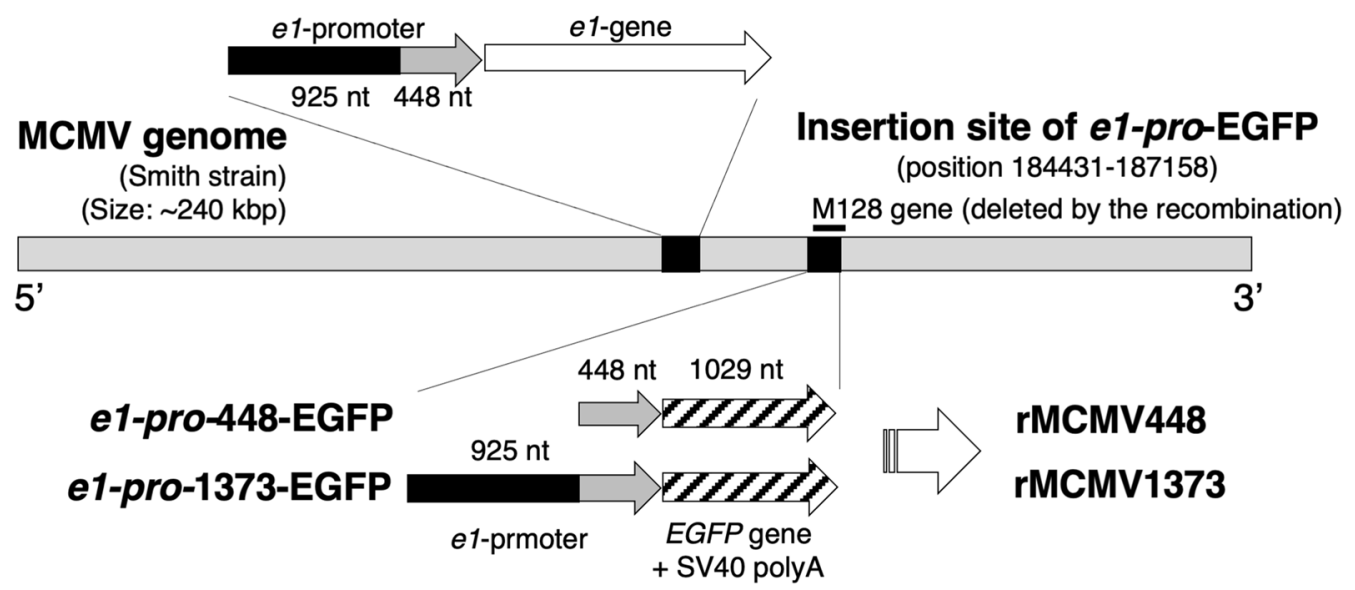

Fig. 1 Constructions of rMCMV448 and rMCMV1373. The arrangement of the original MCMV-e1-pro (position nt 161605 to 162977, black and gray arrow), M112/113 (e1) gene (position nt 162978 to 165076, white arrow) and the insertion site of e1-pro-EGFP (right black box) in the wild type MCMV genome are shown. In this study, an e1-pro-EGFP cassette consisting of the e1-pro fragment (nt -1373 or -448 to + 38 relative to the transcription start site, black and gray or gray arrow, respectively) and EGFP gene with an SV40-derived polyadenylation signal (striped arrows) was inserted into the position between nt 184431 and 187158 (right black box) in wild type MCMV genome by homologous recombination. This recombination causes the deletion of the $\mathrm{nt} 2728$ sequence including the greater part of the M128 gene (black line). During the infection of recombinant viruses, the activation of the inserted e1-pro can be in situ detected as the expression of EGFP. The detailed construction, preparation method and verification of rMCMVs are shown in Additional file 1: Fig. S1 
promoter activation. The detailed construction, preparation method and verification of rMCMVs are shown in Additional file 1: Fig. S1.

\section{Primary neuronal culture}

Primary neuronal cultures were prepared from the CX and HP of gestational day 16 embryos of ICR mice with a minor modification of the method as described in a previous study [27]. Brains were removed from the embryos and put in a plastic dish on ice. The CX and HP were separated from the diencephalon and meninges under a compound microscope and scissored in neurobasal medium (Gibco, \#A2477501). After digestion with $0.125 \%$ trypsin (Gibco, \#27250018) in calcium, magnesium-free PBS and $30 \mathrm{mM}$ glucose at $30{ }^{\circ} \mathrm{C}$ for $30 \mathrm{~min}$, the cells were suspended and dissociated in the plating medium as described below and plated on 12-well plates or coverslips $(18 \times 12 \mathrm{~mm})$ in 12 -well plates, previously coated with poly-D-lysine $(0.1 \mathrm{mg} / \mathrm{ml})$ (SigmaAldrich, \#P7280). The cells were grown in the plating medium consisting of neurobasal medium supplemented with 10\% horse serum (Gibco, \#16050130), 1\% B27 supplement (Gibco, \#17504044), $0.5 \mathrm{mM}$ glutamine, $50 \mu \mathrm{M}$ 2-mercaptoethanohol, penicillin (100 units $/ \mathrm{ml})$ and streptomycin $(50 \mu \mathrm{g} / \mathrm{ml})$. Two days after plating, the cells were treated with 5 -fluoro-2'-deoxyuridine $(0.04 \mathrm{mM})$ (Sigma-Aldrich, \#F0503) for 2 days to inhibit proliferation of non-neuronal cells, and then the medium was refreshed and not changed again. We used primary neuronal cultures for experiments from 9 days after plating. In this study, our primary neuronal culture was predominantly composed of neurons, but certainly contained some non-neuronal cells, neurons, astrocytes and other cells present at an approximate ratio of 90:5:5.

\section{MCMV infection}

MEF and primary neuronal cultures at 2 days or 9 days after plating, respectively, were infected with MCMVs at different multiplicities of infection (MOIs) as follows: MEF at $0.1,0.3$ or 1 plaque forming units (PFU)/cell and primary neuronal cultures at $0.3,1$ or $3 \mathrm{PFU} /$ cell. To determine the time courses of viral titers, MEF and primary neuronal cultures infected with MCMVs at MOIs of 1 and 3, respectively, were used. At different numbers of days post-infection (dpi), three $50-\mu \mathrm{l}$ samples of culture supernatant in each MCMV-infected group were collected. The viral titers were measured by a plaque assay. MEF and primary neuronal cultures on glass coverslips were fixed at 2 and 4 days after the infection, respectively, by $4 \%$ paraformaldehyde (PFA) in $0.1 \mathrm{M}$ phosphate buffer (PB) for $20 \mathrm{~min}$ at room temperature, stored in PBS with $5 \%$ FBS and $0.1 \%$ sodium azide at $4{ }^{\circ} \mathrm{C}$, and followed by the immunofluorescence.
For the infection of the neonatal mouse brain, 1 day after birth, $4 \times 10^{4} \mathrm{PFU}$ of MCMVs in $5 \mu \mathrm{l}$ of minimum essential medium (MEM) was injected into the right cerebral hemisphere of neonatal mice under cryoanesthesia using a 10- $\mu$ l Hamilton syringe with a 27-gauge needle from the midpoint between the ear and eye. At 7 or $11 \mathrm{dpi}$, mice were killed under anesthesia with ether. The brains were removed, stored at $-80{ }^{\circ} \mathrm{C}$ and used for plaque assays or reverse transcription-polymerase chain reaction (RT-PCR) assays. At 3,7 or $11 \mathrm{dpi}$, the brains for histological analysis were fixed by perfusion with $4 \%$ PFA, removed, fixed for 2 days at $4{ }^{\circ} \mathrm{C}$, immersed in $30 \%$ sucrose for 2 days and quickly frozen in $n$-hexane at $80{ }^{\circ} \mathrm{C}$. Coronal sections used for the detection of EGFP fluorescence and immunofluorescence were cut at $60 \mu \mathrm{m}$ using a cryostat and stored in PBS with 5\% FBS and 0.1\% sodium azide at $4{ }^{\circ} \mathrm{C}$, while the sections for the immunohistochemistry were cut at $10 \mu \mathrm{m}$, air-dried and stored at $-80^{\circ} \mathrm{C}$.

\section{Immunofluorescence, immunohistochemistry and cell counts}

MCMV-E1 nuclear antigen (Ag) was detected by mouse monoclonal antibody (mAb) clone D5 (IgG2a; 1:1, [24, 54]). MCMV-IE3 nuclear Ag was detected by rat polyclonal Ab (pAb; 1:1000, [24]). MCMV-M45 cytoplasmic Ag was detected by rat $\mathrm{mAb}$ clone Q3 (1:1, [27]).

For immunofluorescence, in addition to MCMV$\mathrm{E} 1$ or $-\mathrm{M} 45$, neurons were stained by $\mathrm{Ab}$ specific for NeuN (mouse mAb, clone A60, IgG1, 1:500, Millipore, Merck, \#MAB377) or MAP2 (rabbit pAb, 1:100, abcam, \#ab32454 Cambridge, UK). Astrocytes were stained by rabbit pAb specific for GFAP (1:1, DAKO, Agilent, \#GA524, Santa Clara, CA). The following secondary antibodies, purchased from Invitrogen, Thermo Fisher Scientific, were used at a 1:500 dilution; Alexa Fluor 546 anti-mouse IgG2a (\#A-21133), anti-mouse IgG1 (\#A21123), -rabbit IgG (\#A-11035) or -rat IgG (\#A-11081). Nuclei were stained with 4',6-diamidino-2-phenylindole, dihydrochloride (DAPI) (Sigma-Aldrich, \#D9542). Immunostained cells on coverslips or sections were mounted with ProLong Gold antifade reagent (Invitrogen, \#P36934).

For immunohistochemistry, after microwave treatment, brain sections were reacted with anti-E1 mouse $\mathrm{mAb}$ D5, anti-IE3 rat pAb, anti-M45 rat mAb Q3 or antiEGFP rabbit pAb (1:100, abcam, \#ab6556). The sections, except for those reacted with mAb D5, were subsequently reacted with horseradish peroxidase (HRP)-conjugated goat anti-rat IgG pAb (N-Histofine simple stain mouse MAX-PO(Rat); 1:1, Nichirei Bioscience, \#414311, Tokyo, Japan) or HRP-conjugated goat anti-rabbit IgG (N-Histofine simple stain mouse MAX-PO(R); 1:1, Nichirei 
Bioscience, \#414341). The sections reacted with $\mathrm{mAb}$ D5 were reacted with Alexa Fluor 546 goat anti-mouse IgG2a (1:500) and then with HRP-conjugated rabbit antigoat IgG (N-Histofine simple stain mouse MAX-PO(G); 1:1, Nichirei Bioscience, \#414331). The sections were colored with 3,3-diaminobenzidine tetrahydrochloride (DAB; DAKO, \#K3467). Nuclei were counterstained with hematoxylin.

Phase contrast and immunofluorescence images (Figs. 3, 4) were taken using an Olympus IX-70 fluorescence microscope with a DP-70 digital camera system (Olympus, Tokyo, Japan). Cerebral images of EGFP fluorescence (Fig. 6) were taken using a BZ-9000 Biorevo microscope (Keyence, Osaka, Japan). Confocal images were captured using a Leica TCS SP8 microscope with Leica LAS X software (Leica, Wetzlar, German) (Fig. 5) and an Olympus FV1000-D microscope with Fluoview software (Figs. 7,8 ). A stack of 5 images from $0.5-\mu \mathrm{m}$ step slices was combined for the analysis.

At least 3 different samples in each experimental group were used for the analysis. In each coverslip, cell counts from 3 fields $\left(292 \times 220 \mu \mathrm{m} ; 0.064 \mathrm{~mm}^{2} / \mathrm{a}\right.$ field $)$ were averaged. In the coronal sections of the right hemisphere of rMCMV-infected brains, right hemispheres were divided into the PV, HP, and CX regions and the numbers of $\mathrm{EGFP}^{+}$and MCMV-E1 ${ }^{+}$cells in each area at 3, 7, and $11 \mathrm{dpi}$ were counted. Then the numbers of positive cells in the hippocampal and cortical region were combined.

\section{RT-PCR for the semi-quantification of mRNA expression of MCMV-ie3, -e 1 and EGFP genes in brains infected with wild type MCMV or rMCMVs}

Total RNA was extracted from the frozen brain samples using ISOGEN (Wako Chemical, Osaka, Japan), purified with a RNeasy Mini Kit (Qiagen, Hilden, Germany, \#74104) and treated with RNase-free DNase I (Qiagen, \#79254), according to the manufacturer's instructions. One hundred ng of cDNA synthesized using a SuperScript III First Strand Synthesis kit with random primers (Invitrogen, Thermo Fisher Scientific, \#18080-051) was used for each PCR reaction. The $\beta$-actin gene was amplified from each sample as a control. The gene expression levels of the target genes were normalized to the expression levels of the $\beta$-actin gene. The primers used for the detection of the indicated mRNAs were as follows: MCMV-ie3, 5'-ACG TGG GGA ATG ATA ACA GC-3' (forward) and $5^{\prime}$ - TCC TGA GGC TGC TGA AAA AT-3' (reverse); MCMV-e1, 5' - CCA ACG GTA CCC TTC ATA GG-3' (forward) and 5' - CAG CTT CGT CTG CAT TAC CA-3' (reverse); EGFP, 5'-TGA ACC GCA TCG AGC TGA AGG G-3' (forward) and 5' - TCC AGC AGG ACC ATG TGA TCG C-3' (reverse); $\beta$-actin, 5'-GTG CTA
TGT TGC CCT GGA TT-3' (forward) and 5'-TGG AGT TGA AGG GTG GTC TC-3' (reverse).

\section{Statistical analyses}

Numerical results were expressed as the mean \pm standard error of mean (SEM) obtained from at least three independent experiments. Statistical analysis was performed using an unpaired 2-tailed Student's t test. Probability values $(p)<0.01$ were considered to be significant.

\section{Results}

MCMV e1-pro activation during infection in MEF and primary neuronal cultures

Growth of wild type MCMV and rMCMVs in MEF and primary neuronal cultures

To investigate the effects of the recombination of wild type MCMV on in vitro viral replication, we examined the growth of wild type MCMV, rMCMV1373 and rMCMV448 in MEF and primary neuronal cultures. In MEFs, which are known to be fully permissive for MCMV replication, all viruses showed rapid exponential growth (Fig. 2a). In primary neuronal cultures, the growth of all viruses was very low and prolonged, and showed persistent infection as compared with the growth in MEFs (Fig. 2b). However, in both cultures there were no significant differences in the titers at any time point among three viruses. Therefore, it was considered that the recombination of wild type MCMV in this study had almost no effect on viral replication.

\section{No difference in the activation of the MCMV e1-promoter between rMCMV-1373 and -448 infected MEFs}

To investigate the difference in MCMV e1-pro activation as a reporter of EGFP between non-neuronal cells and neurons, we examined EGFP expression in MEF and primary neuronal cultures infected with rMCMVs (Figs. 3, 4).

In MEFs infected with either rMCMV1373 or rMCMV448 at $2 \mathrm{dpi}$, increases in MOI led the increases in the numbers of $\mathrm{EGFP}^{+}$cells in parallel with those of $\mathrm{E}^{+}$cells (Fig. $3 \mathrm{u}$ ). Virus-infected cells appeared round in shape, indicating a cytopathic effect (CPE) as a sign of the onset of lytic cell death (Fig. 3a, e) and, 4 dpi later, most of the infected cells were detached. There was no significant difference in the numbers of $\mathrm{EGFP}^{+}$ or $\mathrm{E}^{+}{ }^{+}$cells between rMCMV1373- and rMCMV448infected MEFs (Fig. 3b, c, f, g, u). At any MOI, the proportion of $\mathrm{EGFP}^{+}$cells to $\mathrm{E}^{+}$cells was around $90 \%$ or more (Fig. $3 \mathrm{u}$ ), and the immunofluorescence for E1 demonstrated that almost all $\mathrm{EGFP}^{+}$cells expressed E1 in MEFs infected with either rMCMV1373 or rMCMV448 (Fig. 3d, h). These results indicate that the activation of the inserted e1-pro in the MCMV genome 

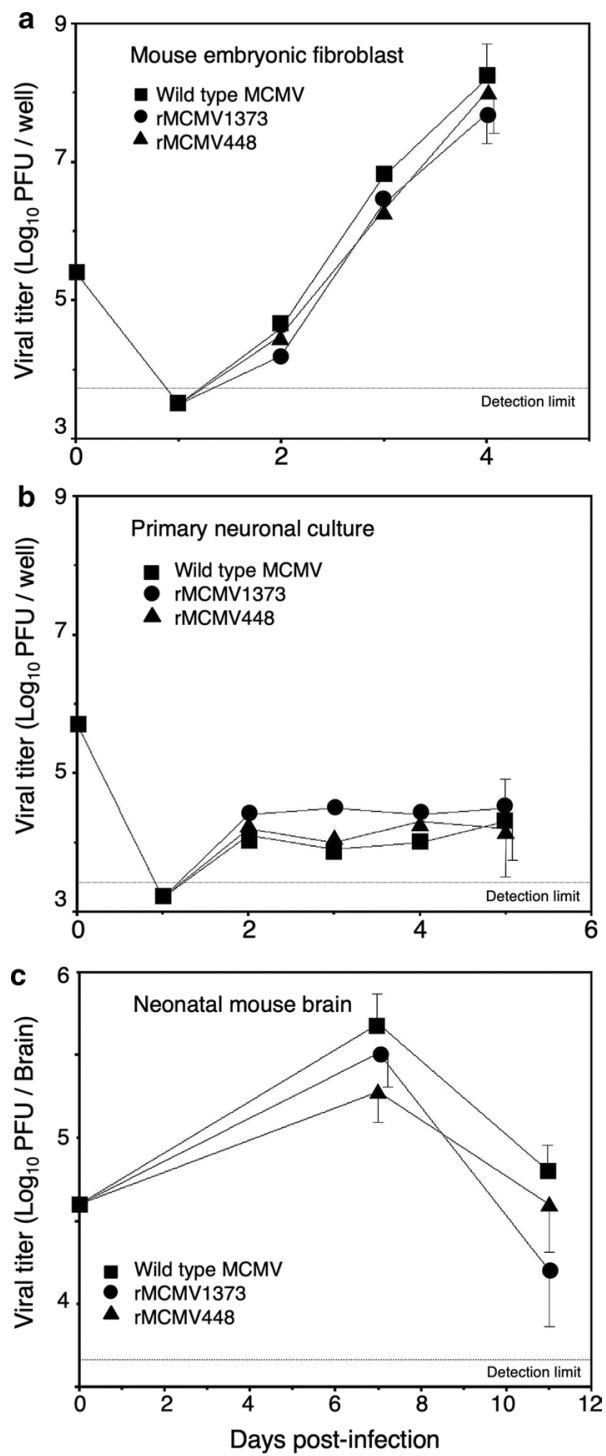

Fig. 2 Viral growth in MEFs (a), primary neuronal cultures (b) and neonatal mouse brains (c) infected with wild type MCMV ( $\mathbf{\square}$ ) rMCMV1373 (-) or rMCMV448 ( $\mathbf{\Delta})$. MEF and primary neuronal cultures were infected with MCMVs at MOls of 1 and 3, respectively. Neonatal mice were intracerebrally infected with $4 \times 10^{4} \mathrm{PFU}$ of MCMVs at 1 day after birth. Viral loads in each culture supernatant or mouse brain were determined by infectious viral titers. The dotted line indicates the detection limit. Mean \pm SEM of 3 samples in infected cultures or mouse brains in each experimental group are shown well represents the actual production of E1-protein, and that the truncation of the e1-pro-1373 sequence had no effect on the activation of e1-pro in rMCMVinfected MEFs.
Distinct neuronal activation of the MCMV e1-promoter in rMCMV1373-infected primary neuronal cultures but not in rMCMV448-infected cultures

In rMCMV-infected primary neuronal cultures at $4 \mathrm{dpi}$, the averaged percentages of neuronal marker (NeuN)and glial marker (GFAP)-positive cells were $87.6 \pm 3.6 \%$ and $4.70 \pm 0.15 \%$, respectively. rMCMV-infected primary neuronal cultures scarcely demonstrated a CPE or detachment (Fig. 3i, o), unlike the rMCMV-infected MEFs as described above. In rMCMV1373-infected neuronal cultures, increases in MOI led the increases in the numbers of $\mathrm{EGFP}^{+}$cells in parallel with those of $\mathrm{E}^{+}$cells, and the proportion of $\mathrm{EGFP}^{+}$cells to $\mathrm{E}^{+}$cells was about $90 \%$, as observed in rMCMV-infected MEFs (Fig. 3j-l, u). Most of EGFP ${ }^{+}$cells showed a neuronal morphology; that is, round soma with elongated neurites (Fig. 3j). Immunofluorescence demonstrated that almost all EGFP ${ }^{+}$cells expressed E1 (Fig. 3k, l). Furthermore, the cells expressing both EGFP and NeuN accounted for at least about $90 \%$ of $\mathrm{EGFP}^{+}$cells (Fig. 3v).

Conversely, in the rMCMV448-infected neuronal cultures, the numbers of $\mathrm{EGFP}^{+}$cells were markedly reduced and ranged from 12 to $24 \%$ of those in the rMCMV1373-infected neuronal cultures (Fig. 3v), although there was no significant difference in numbers of $\mathrm{E}^{+}{ }^{+}$cells between the rMCMV1373- and rMCMV448infected neuronal cultures at any MOI (Fig. 3k, q, v). Immunofluorescence revealed the presence of very few $\mathrm{EGFP}^{+}$cells (Fig. 3p, r, t, arrowheads); however, those present did express E1 (Fig. 3q, r, arrowheads), whereas little EGFP was expressed in NeuN-positive neurons in comparison with rMCMV1373-infected neuronal cultures (Fig. 3v). In addition, as observed for the expression of E1, MCMV cytoplasmic antigen M45 was also expressed in almost all the cells with a neuronal morphology in either rMCMV1373- or rMCMV448-infected neuronal culture (Fig. 3m, n, s, t).

Collectively, e1-pro-1373 was similarly activated in neurons as in MEFs (Fig. 3b, j), while e1-pro-448 was hardly activated in neurons despite adequate activation in MEFs (Fig. 3f, p). However, there were no fundamental differences in the kinetics of viral growth or the expression of viral antigens between rMCMV1373 and rMCMV448 in primary neuronal cultures (Figs. 2b, 3k, $\mathrm{m}, \mathrm{q}, \mathrm{s}, \mathrm{v})$. Therefore, the upstream region from nt -449 to -1373 in the e1-pro-1373 sequence is necessary for the neuron-specific activation of e1-pro.

\section{The MCMV e1-promoter is activated in neurons} but not differentiated astrocytes in primary neuronal cultures To comfirm the distinct neuronal activation of e1-pro-1373, immunofluorescence for neuronal and glial 


\begin{abstract}
(See figure on next page.)
Fig. 3 a-t Detection of EGFP, MCMV-E1 and MCMV-M45 in rMCMV1373- or 448-infected MEF and primary neuronal cultures. Either rMCMV was allowed to infect both cell cultures at a MOI of 1. Virus-infected MEF and primary neuronal cultures were sampled at 2 and 4 dpi, respectively. a-d rMCMV1373-infected MEFs. e-h rMCMV448-infected MEFs. i-n rMCMV1373-infected primary neuronal culture. o-t rMCMV448-infected primary neuronal culture. In each rMCMV-infected culture, phase contrast $(\mathbf{a}, \mathbf{e}, \mathbf{i}, \mathbf{o})$ and fluorescence views of EGFP $(\mathbf{b}, \mathbf{f}, \mathbf{j}, \mathbf{n}, \mathbf{p}, \mathbf{t})$, immunofluorescence for MCMV-E1 (red) (c, g, $\mathbf{k}, \mathbf{q})$ and MCMV-45 (red) ( $\mathbf{m}, \mathbf{s})$ and merged images of EGFP and MCMV-E1 (d, $\mathbf{h}, \mathbf{l}, \mathbf{r})$ are shown. Arrow heads in $\mathbf{p}-\mathbf{t}$ indicate $\mathrm{EGFP}^{+}$cells. Scale bar: $50 \mu \mathrm{m}$. u, $\mathbf{v}$ Comparison of the numbers of EGFP ${ }^{+}$or MCMV-E1 ${ }^{+}$cells in MEF (u) and primary neuronal cultures $(\mathbf{v})$ infected with rMCMV1373 or rMCMV448. MEF and primary neuronal cultures were infected with rMCMVs at three different MOls and analyzed at 2 and 4 dpi, respectively. Additionally, in primary neuronal cultures $(\mathbf{v})$ the numbers of cells doubly positive for EGFP and NeuN as shown in Fig. 4 were counted. The cell counts of 3 different fields $\left(292 \times 220 \mu \mathrm{m} ; 0.064 \mathrm{~mm}^{2} / \mathrm{a}\right.$ field) were averaged in each coverslip. Mean \pm SEM of 3 different coverslips in each experimental group are shown $\left(\mathrm{E}^{+}{ }^{+}\right.$, white bar; $\mathrm{EGFP}^{+}$, gray bar; $\mathrm{EGFP}^{+}$NeuN ${ }^{+}$, black bar). Averaged numbers of total cells as DAPI ${ }^{+}$nuclei were $339 \pm 31 / 0.01 \mathrm{~mm}^{2}$ and $305 \pm 20 / 0.01 \mathrm{~mm}^{2}$, in virus-infected MEF and primary neuronal cultures, respectively. The averaged percentage of $\mathrm{NeuN}^{+}$cells in primary neuronal cultures infected with rMCMVs was $87.6 \pm 3.6 \%{ }^{*} p<0.01$ vs. corresponding rMCMV1373-infected culture in each experimental group by an unpaired 2-tailed Student's t-test
\end{abstract}

markers was performed in rMCMV-infected neuronal cultures. In rMCMV1373-infected neuronal cultures, $90 \%$ of $\mathrm{EGFP}^{+}$cells were $\mathrm{NeuN}^{+}$neurons (Figs. 3v, 4a-c). Most of the $\mathrm{GFAP}^{+}$cells were differentiated astrocytes, which displayed a coral-like shape (Fig. 4e, f). Interestingly, EGFP was not expressed in these astrocytes (Fig. 4d-f). In addition, very few cells doubly positive for EGFP and GFAP showed a round shape, suggesting CPE (Fig. 4d-f, arrowheads). On the other hand, in rMCMV448-infected neuronal cultures, there were very few $\mathrm{EGFP}^{+}$cells, and most of them showed a round shape and were doubly positive for GFAP (Fig. 4j-l, arrowheads) but not for NeuN (Fig. $4 \mathrm{~g}-\mathrm{i}$, arrowheads). These $\mathrm{EGFP}^{+} / \mathrm{GFAP}^{+}$round cells found in both rMCMVinfected primary neuronal cultures were supposed to be $\mathrm{GFAP}^{+}$immature progenitor or glial cells and permissive for viral replication as with the MEFs as observed above.

An examination of the immunofluorescence for rMCMV1373-infected neurons using an antibody against MAP2 as another neuronal marker demonstrated that EGFP was accurately co-localized with MAP2 (Fig. 5a-c) based on detailed fluorescent images obtained by confocal laser microscopy. On the contrary, EGFP was not expressed in GFAP $^{+}$astrocytes (Fig. 5d-f).

From these results, we suppose that the activation of e1-pro-1373 but not e1-pro-448 is indispensable for the production of the E1-protein in primary neurons. In addition, differentiated primary astrocytes are not permissive in terms of MCMV infection in vitro.

\section{MCMV-e1-promoter activation during infection of neonatal mouse brains \\ Growth of wild type MCMV and rMCMVs in the postnatal brains}

To investigate the effects of the recombination of wild type MCMV on in vivo viral replication, we examined the growth of wild type MCMV and rMCMVs in neonatal mouse brains. The intracerebral viral growth peaked around $7 \mathrm{dpi}$ in the ICR mice inoculated with any of the three viruses (Fig. 2c) as reported previously [29]. There were no significant differences in the intracerebral titers at any time point among three viruses, although the viral titer of wild type MCMV was slightly higher than that of rMCMVs. These results indicate that the recombination of wild type MCMV in this study had no significant effect on viral replication and pathogenicity as observed in MEF and primary neuronal cultures.

\section{Comparison of the kinetics of the MCMV e1-promorter activity and MCMV-E1-positive cells in the developing brains infected with rMCMV1373 and rMCMV448}

In the developing cerebrums of neonatal mice infected with either rMCMV1373 or rMCMV448, MCMV e1-pro activity as a reporter of EGFP first appeared in the PV region (Fig. 6a, d). At 7 dpi in the rMCMV1373-infected cerebrum the region of $\mathrm{EGFP}^{+}$cells extended from the PV region to the HP and CX (Fig. 6b), while in the rMCMV448-infected cerebrum the region of $\mathrm{EGFP}^{+}$ cells still limited to the PV region, (Fig. 6e). At $11 \mathrm{dpi}$ in rMCMV1373-infected cerebrum $\mathrm{EGFP}^{+}$cells continued to remain in the $\mathrm{HP}$ and $\mathrm{CX}$ although $\mathrm{EGFP}^{+}$cells disappeared from the PV region (Fig. 6c, g). Almost all of the remaining cells in the HP or CX displayed a morphology of the pyramidal neuron. Detailed images of these EGFP ${ }^{+}$ cells showed neurons with neuronal somas and dendrites (Fig. 6g, inner panels). However, in the rMCMV448infected cerebrum at $11 \mathrm{dpi}$, the EGFP fluorescence disappeared entirely (Fig. 6f).

At both 7 and $11 \mathrm{dpi}$ in the rMCMV1373-infected cerebrums the localization of $\mathrm{EGFP}^{+}$cells closely corresponded to that of $\mathrm{E} 1^{+}$cells (Fig. $7 \mathrm{a}-\mathrm{d}$ ). In either the PV region or the combined region of the $\mathrm{HP}$ and $\mathrm{CX}$, there was no significant difference in cell numbers between $\mathrm{EGFP}^{+}$cells and $\mathrm{E}^{+}{ }^{+}$cells (Fig. $7 \mathrm{i}, \mathrm{j}$ ). In the PV region of the rMCMV448-infected cerebrums, the localization of $\mathrm{EGFP}^{+}$cells closely corresponded to that of $\mathrm{E} 1^{+}$cells 


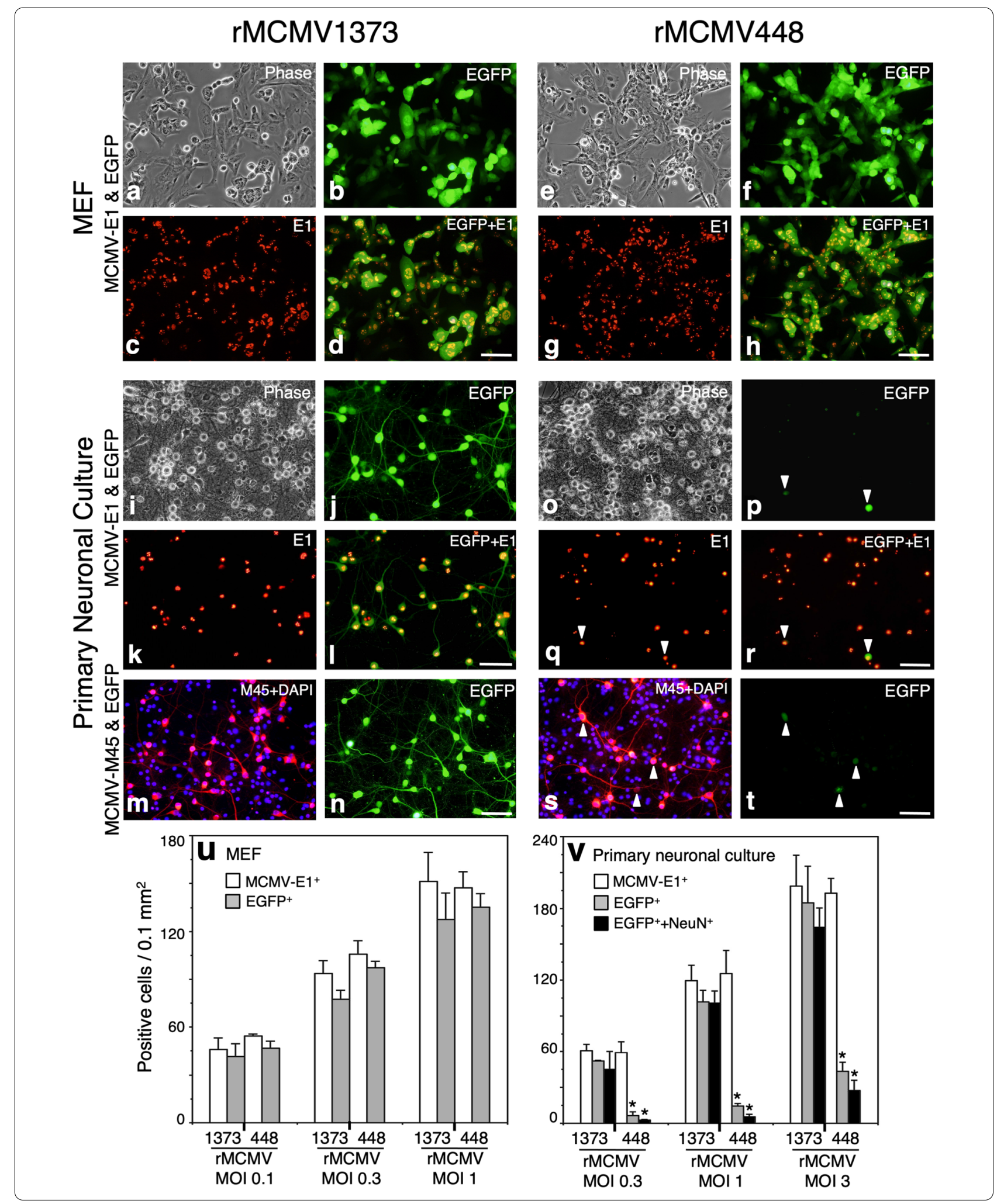



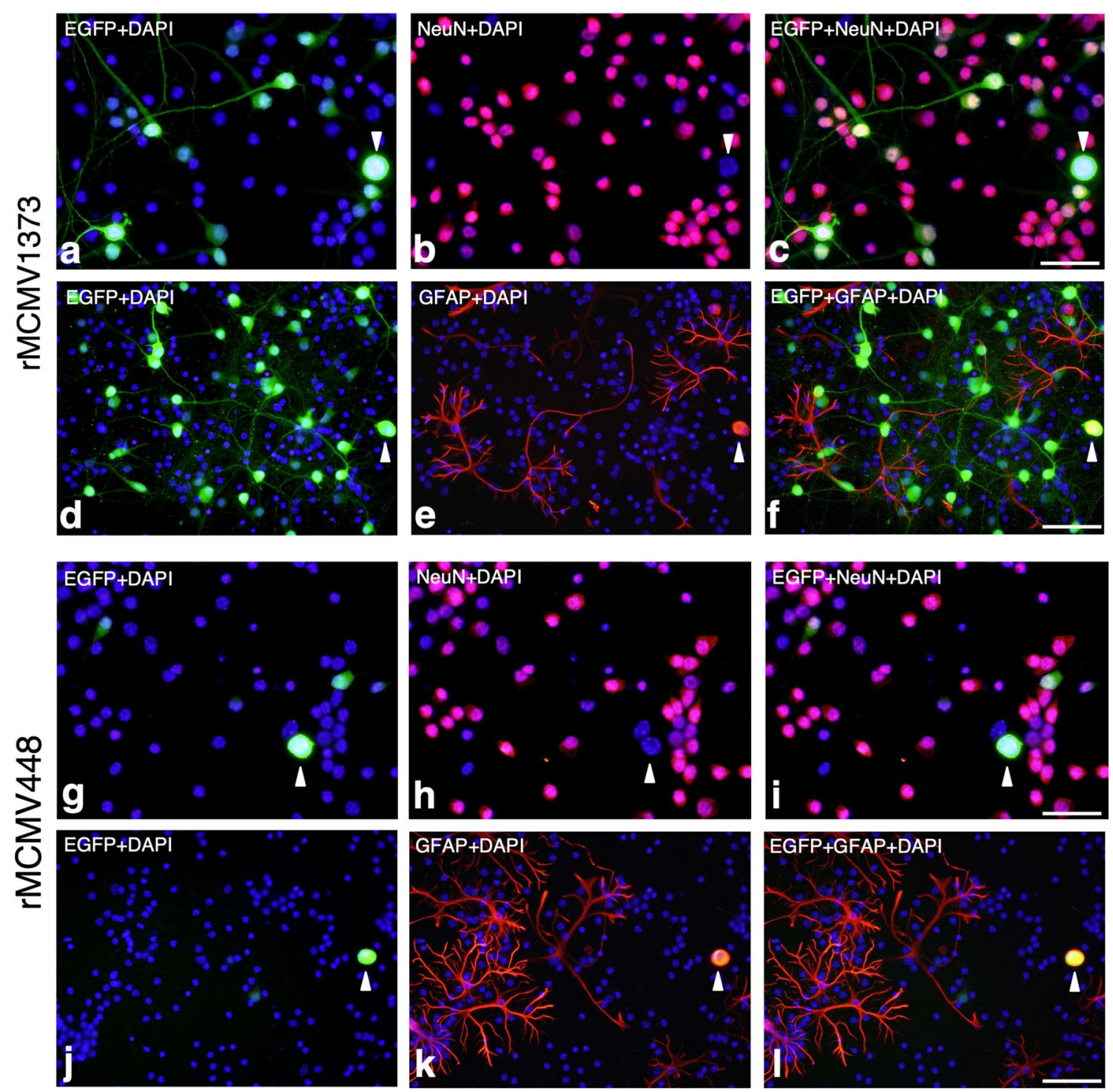

Fig. 4 Identification of EGFP+ cell types in primary neuronal cultures infected with rMCMV1373 (a-f) or rMCMV448 (g-I) as shown in Fig. 3i-t. Immunofluorescence were performed using antibodies against $\operatorname{NeuN}(\mathbf{a}-\mathbf{c}, \mathbf{g}-\mathbf{i})$ and GFAP $(\mathbf{d}-\mathbf{f}, \mathbf{j}-\mathbf{I})$ as neuronal and glial cell makers, respectively. Nuclei are stained with DAPI. In each rMCMV-infected culture, fluorescence views of EGFP $(\mathbf{a}, \mathbf{d}, \mathbf{g}, \mathbf{j})$, immunofluorescence for NeuN (purple) (b, $\mathbf{h}$ ) and GFAP (red) $(\mathbf{e}, \mathbf{k})$ and merged images of EGFP and cell markers $(\mathbf{c}, \mathbf{f}, \mathbf{i}, \mathbf{l})$ are shown. Arrow heads indicate $\mathrm{EGFP}^{+} / \mathrm{NeuN}^{-} \mathrm{or} \mathrm{EGFP}^{+} / \mathrm{GFAP}^{+}$round cells. In rMCMV1373-infected primary neuronal cultures almost all EGFP+ cells are neurons (a-c), while in rMCMV448-infected cultures there are very few EGFP ${ }^{+}$neurons $(\mathbf{g}-\mathbf{i})$. In both rMCMV1373- and rMCMV448-infected primary neuronal cultures (f, I), EGFP is not expressed GFAP' differentiated astrocyte with a coral-like shape, though very few EGFP ${ }^{+} / G F A P^{+}$round cells are found. Scale bars: $\mathbf{a}-\mathbf{c}, \mathbf{g}-\mathbf{i} 25 \mu \mathrm{m} ; \mathbf{d}-\mathbf{f}, \mathbf{j}-\mathbf{I} 50 \mu \mathrm{m}$

(Fig. 7e, f). At all time-points the numbers of EGFP ${ }^{+}$cells were not significantly different from those of $\mathrm{E}^{+}$cells (Fig. 7i). On the contrary, at all time-points in the HP and $\mathrm{CX}$ of the rMCMV448-infected cerebrum $\mathrm{EGFP}^{+}$cells were negligible (Fig. 7e, g) despite the presence of similar numbers of $\mathrm{E}^{+}$positive cells in the rMCMV1373infected cerebrum (Fig. 7f, h, j).

These results suggest that e1-pro-448 is not activated in hippocampal or cortical neurons, but is sufficiently activated in the cells in the PV region and that the upstream region from nt -449 to -1373 in the e1-pro-1373 sequence is indispensable for the activation of e1-pro in hippocampal and cortical neurons.

\section{Activation of MCMV e1-pro-1373 in neurons but not in astrocytes during the postnatal cerebral development}

To clarify the exclusive neuronal activation of e1-pro-1373 during the postnatal cerebral development, 

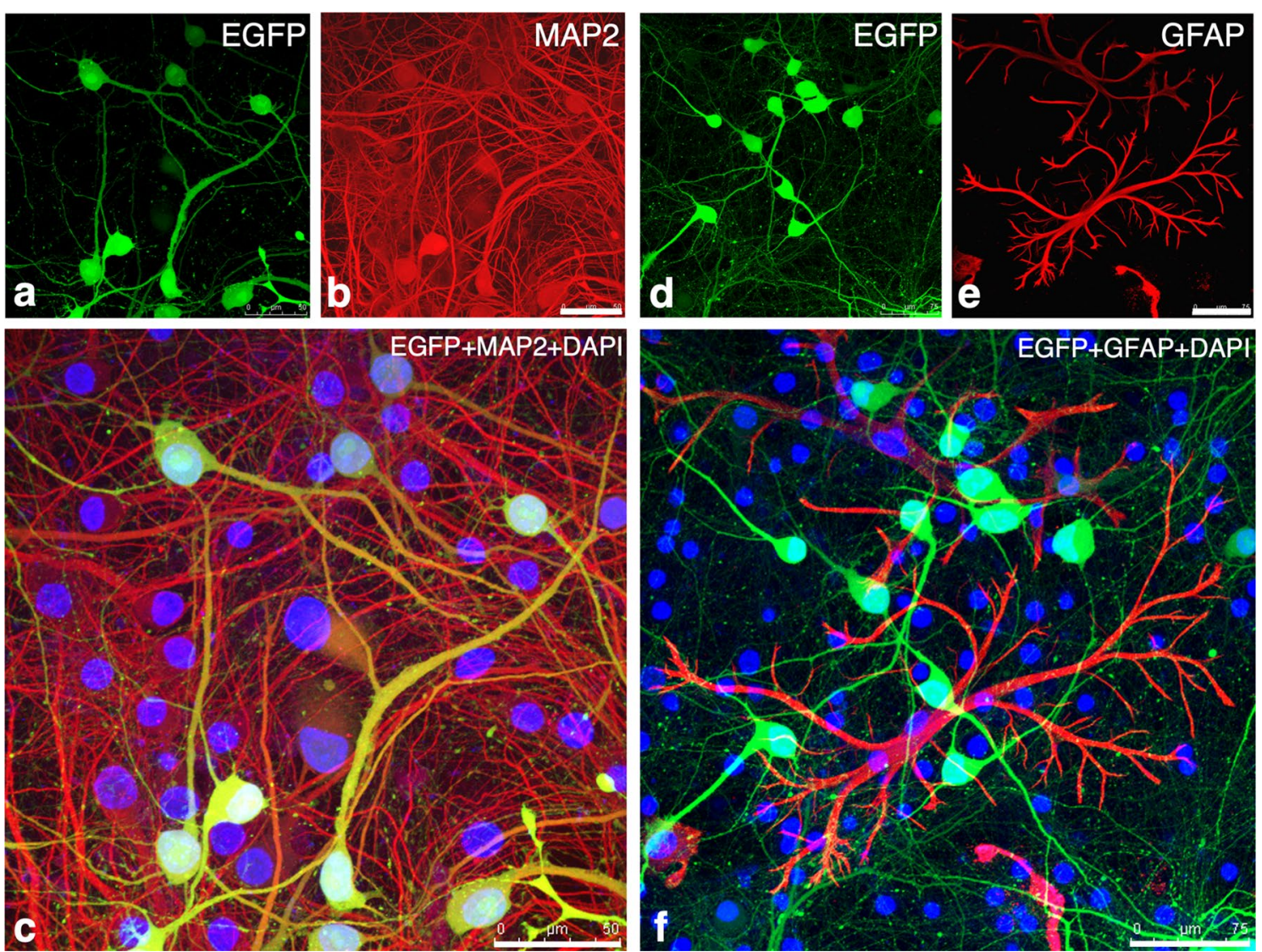

Fig. 5 Detailed fluorescence images obtained by confocal laser microscope in rMCMV1373-infected primary neuronal cultures as shown in Fig. 4. The images demonstrate the distinct co-localization of EGFP and the neuronal marker (a-c) but not the astrocyte marker (d-f). a A fluorescence image of EGFP. $\mathbf{b}$ Immunofluorescence for MAP2 (red) in the same field as $\mathbf{a}$. MAP2 is expressed in numerous primary neuron dendrites and somas. $\mathbf{c}$ A merged image of $\mathbf{a}$ and $\mathbf{b}$. EGFP ${ }^{+}$areas appear yellowish because of the co-localization of EGFP and MAP2, indicating that e1-pro-1373 is distinctly activated in neurons, as demonstrated in Fig. 4. Nuclei are stained with DAPI. $\mathbf{d}$ Another fluorescence image of EGFP. e Immunofluorescence for GFAP (red) in the same field as $\mathbf{d}$. GFAP is expressed in differentiated astrocytes with a coral-like shape, as demonstrated in Fig. 4 . $\mathbf{f}$ A merged image of $\mathbf{d}$ and $\mathbf{e}$. EGFP is not co-localized with GFAP, indicating that the activation of e1-pro-1373 does not occur in differentiated astrocytes. Nuclei are stained with DAPI. Scale bars: a-c $50 \mu \mathrm{m} ; \mathbf{d}-\mathbf{f} 75 \mu \mathrm{m}$

the immunofluorescence for cellular markers was performed in rMCMV1373-infected cerebrums. At $7 \mathrm{dpi}$ in the CX and HP, EGFP was expressed mostly in the neurons, though $\mathrm{EGFP}^{+}$non-neuronal cells including vascular endothelial cell and perivascular macrophages/ microglia were also found (data not shown). At $11 \mathrm{dpi}$ these $\mathrm{EGFP}^{+}$non-neuronal cells disappeared and EGFP was exclusively expressed in pyramidal neurons positive for NeuN (Fig. 8a-c). At all time-points in the CX and HP, no EGFP expression was observed in GFAP $^{+}$ differentiated astrocytes (Fig. 8d-f).

These results clearly demonstrated that the upstream region from nt -449 to -1373 in the e1-pro- 1373 sequence is necessary for the exclusive activation of e1-pro in cerebral neurons, particularly during the postnatal period from around 1 to 2 weeks (the second postnatal week). In addition, differentiated astrocytes are not permissive for MCMV infection as observed in vitro.

\section{Expression of MCMV antigens and the activation of MCMV e1-pro-1373, but not -448, exclusively in cerebral neurons, particularly around the second postnatal week of cerebral development}

To precisely investigate the expression of MCMV antigens in addition to E1 and the activation of e1-pro in the cerebrum, particularly around the second postnatal week, immunohistochemical studies for MCMV-IE3, -E1, -M45 and EGFP were performed in the cerebrum infected with either rMCMV1373 or rMCMV448 at $11 \mathrm{dpi}$. MCMVIE3, which is necessary to activate e1-pro [34, 39], was expressed to a similar level as E1 in the nuclei of hippocampal neurons of the rMCMV-infected cerebrum (Fig. 9a, b, e, f). MCMV-M45, which is known to inhibit 


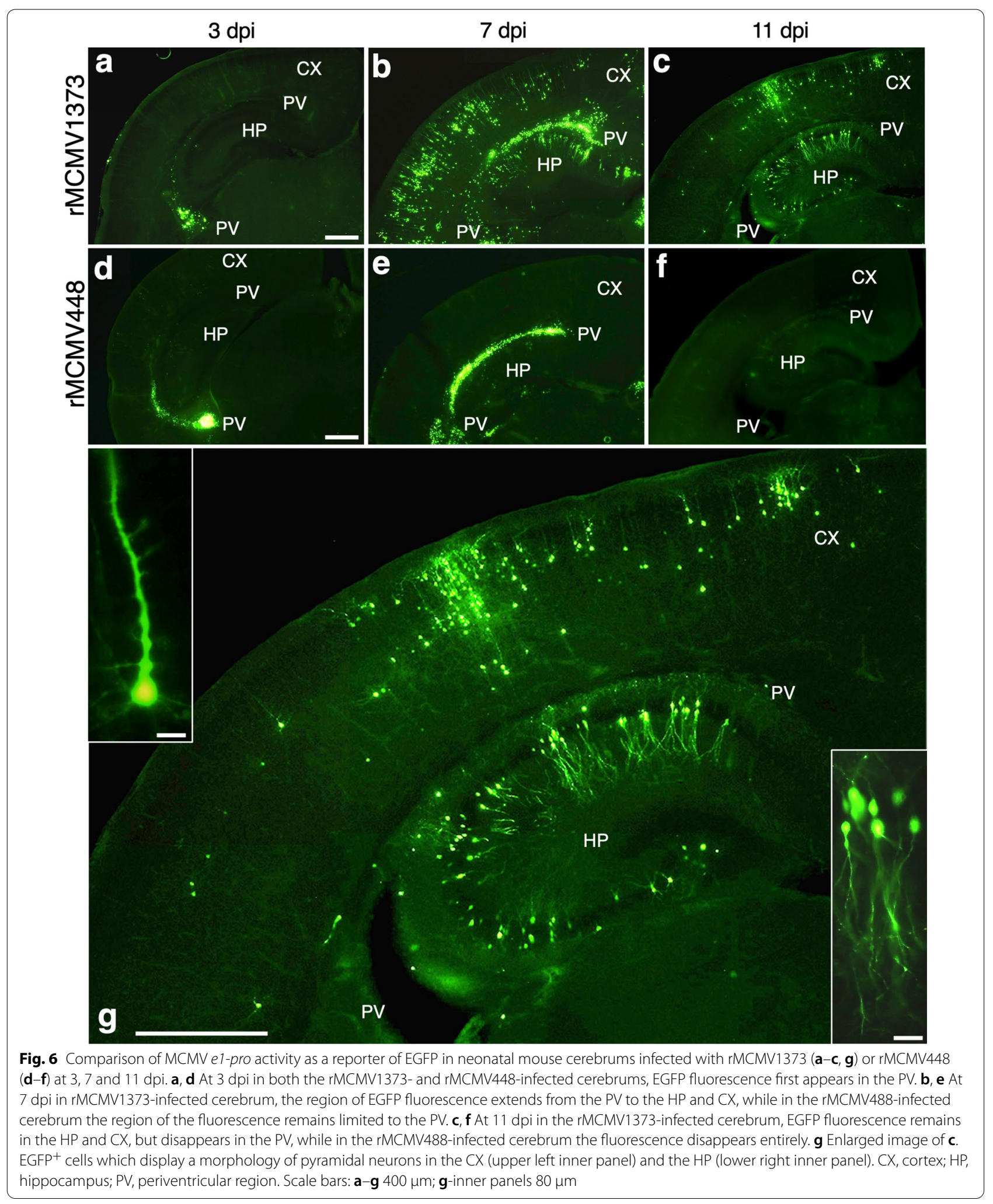




\section{(See figure on next page.)}

Fig. 7 a-h Detection of EGFP and MCMV-E1 in neonatal mouse cerebrums infected with rMCMV1373 or rMCMV448 at 7 and 11 dpi. a-d rMCMV1373-infected cerebrums at 7 (a, b) and 11 dpi (c, d). e-h rMCMV448-infected cerebrum at 7 (e, f) and 11 dpi (g, h). In each rMCMV-infected cerebrum, fluorescence views of EGFP $(\mathbf{a}, \mathbf{c}, \mathbf{e}, \mathbf{g})$ and immunofluorescence for MCMV-E1 (red) $(\mathbf{b}, \mathbf{d}, \mathbf{f}, \mathbf{h})$ in the same field as the EGFP image are shown. Nuclei are stained with DAPI. CX, cortex; HP, hippocampus; PV, periventricular region. Scale bars: $\mathbf{a}-\mathbf{h} 150 \mu \mathrm{mm}$. $\mathbf{i}$, j Kinetics of EGFP+ and $\mathrm{MCMV}-\mathrm{E} 1^{+}$cells in the coronal sections of the right hemisphere of $r M C M V$-infected brains. Right hemispheres were divided into the PV, HP, and CX regions. The numbers of positive cells in each area at 3,7, and 11 dpi were counted and the numbers of positive cells in the hippocampal and cortical region were combined. $\mathbf{i}$ Kinetics of $\mathrm{E}^{+}{ }^{+}$or EGFP+ ${ }^{+}$cells in the PV region. $\mathbf{j}$ Kinetics of $\mathrm{E}^{+}{ }^{+}$or $\mathrm{EGFP}{ }^{+}$cells in the HP and $\mathrm{CX}$ regions. Mean \pm SEM of 3 mouse brains in each experimental group are shown (E1 ${ }^{+}$cells, white bar; EGFP ${ }^{+}$cells, gray bar). ${ }^{*} p<0.01$ vs. corresponding rMCMV1373-infected HP and CX in each experimental group by an unpaired 2-tailed Student's t-test

necrosis of MCMV-infected cells [57], was also expressed in the cytoplasm of hippocampal neurons, preserving their pyramidal morphology (Fig. 9c, g). On the contrary, EGFP was not expressed in the rMCMV448-infected HP (Fig. 9h) despite sufficient expression of IE3, E1 and M45 (Fig. 9e-g), while in the rMCMV1373-infected HP, EGFP was strongly expressed in the whole cell body of pyramidal neurons (Fig. 9d).

These results confirm that the upstream region from nt -449 to -1373 in the $e 1-$ pro- 1373 sequence is necessary for the neuron-specific activation of e1-pro associated with a unique persistent infection during the second postnatal week.

\section{Transcription of MCMV-ie3, -e1 and EGFP $m R N A$}

\section{in the cerebrums infected with wild type MCMV and rMCMVs}

We investigated the transcription of MCMV-E1 and EGFP mRNA in the cerebrums infected with wild type MCMV and rMCMVs by RT-PCR. In the cerebrums infected with any MCMVs, RT-PCR signals of the transcripts of IE3 and E1 mRNA were detected at both 7 and $11 \mathrm{dpi}$, although the transcriptions of IE3 and E1 mRNA at $11 \mathrm{dpi}$ were relatively lower than those at $7 \mathrm{dpi}$ (Fig. 10). This reduction in E1 mRNA transcription at 11dpi supported the results that viral growth and the number of $\mathrm{E} 1^{+}$cells in virus-infected cerebrums peaked around $7 \mathrm{dpi}$ and decreased at $11 \mathrm{dpi}$ in any MCMV, as described above (Fig. 7, 8). On the contrary, the transcripts of EGFP mRNA in the rMCMV448-infected cerebrum disappeared at $11 \mathrm{dpi}$ despite sufficient MCMV-E1 mRNA transcription.

Concerning the kinetics of EGFP expression in the virus-infected cerebrums (Fig. 7, 10), it is thought that EGFP mRNA transcription would be derived from both neurons and non-neuronal cells in the rMCMV1373infected cerebrums. However, the transcripts in the rMCMV448-infected cerebrums were derived from non-neuronal cells. Furthermore, EGFP mRNA transcription in the rMCMV1373-infected cerebrums at $11 \mathrm{dpi}$ is considered to represent the almost complete neuron-specific transcription of EGFP. Therefore, these transcriptional analyses are consistent with the concept that the upstream region from nt -449 to -1373 in the e1-pro-1373 sequence is necessary for the exclusive activation of e1-pro in cerebral neurons, particularly during the second postnatal week of cerebral development.

\section{Discussion}

The brain is the major target organ in congenital CMV infection. Although multiple mechanisms have been proposed to play potential roles in brain abnormalities induced by $\mathrm{CMV}$, there are still unknown problems, especially in terms of long-term abnormalities [14]. The study of human subjects for congenital CMV infection has obvious limitations, particularly those of focusing on spaciotemporal analysis, and those on the brain as a whole, although cerebral organoid cultures have been developed using human materials [25]. We have studied the pathogenesis of the developmental disorders in mouse models using MCMV $[55,56]$. MCMV shows similar characteristics to HCMV in terms of cell tropism, immunity in host-pathogen interactions [42] and genomic composition $[35,41]$.

The susceptibility to CMV and outcomes of brain abnormalities are closely related to not only the gestational age at infection but also the permissiveness of different brain cell types such as NSPCs, neurons, glial cells and macrophages [14]. Among these cell types, it was previously reported that the postnatal developing cerebral neurons in mice displayed a unique persistent infection with the expression of MCMV e1 gene (M112-113) product (E1) [48]. Then, transgenic mice carrying the long e1-pro-lac $Z$ reporter construct consistently demonstrated the e1-pro activation specifically in their neurons [3]. In this study we sought to generate the rMCMVs carrying constructs made up of different lengths of e1-pro connected with an EGFP reporter in order to determine the spaciotemporal activation of e1-pro during actual MCMV infection in vitro and in vivo. We have, for the first time, elucidated that the upstream sequence from nt -449 to -1373 in the longer e1-pro-1373 is necessary for the neuron-specific activation of e1-pro and the unique persistent infection in postnatal developing cerebral neurons, unlike the situation of non-neuronal cells. 


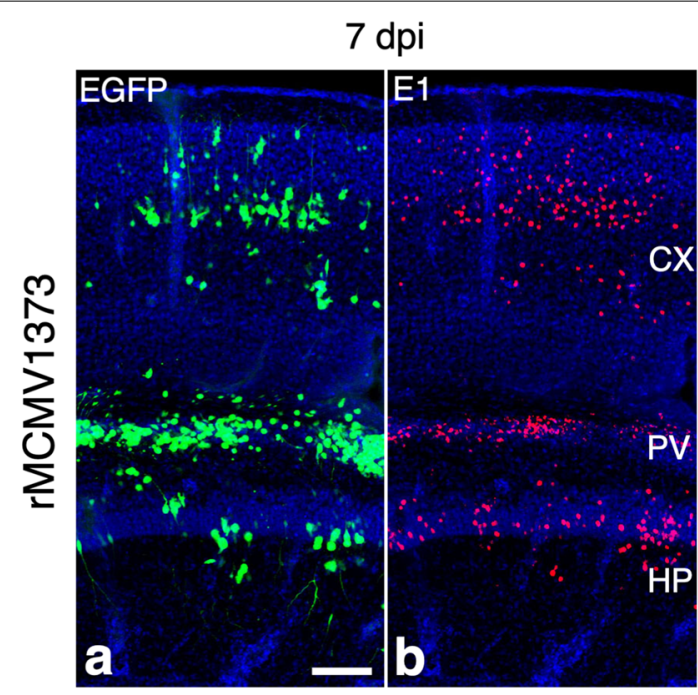

$11 \mathrm{dpi}$

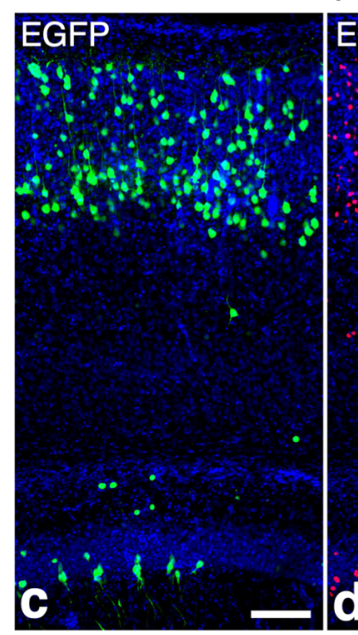

E1
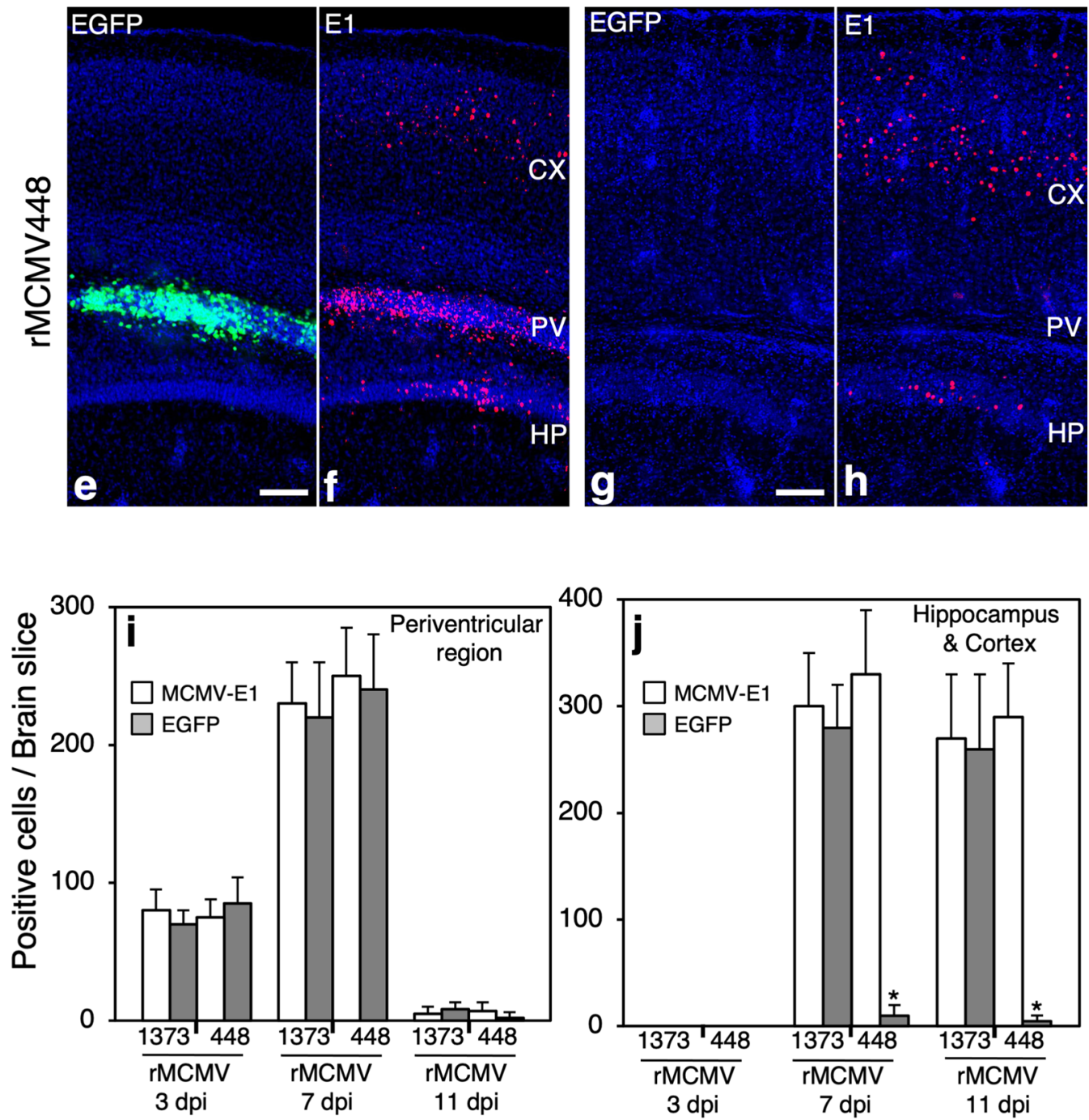

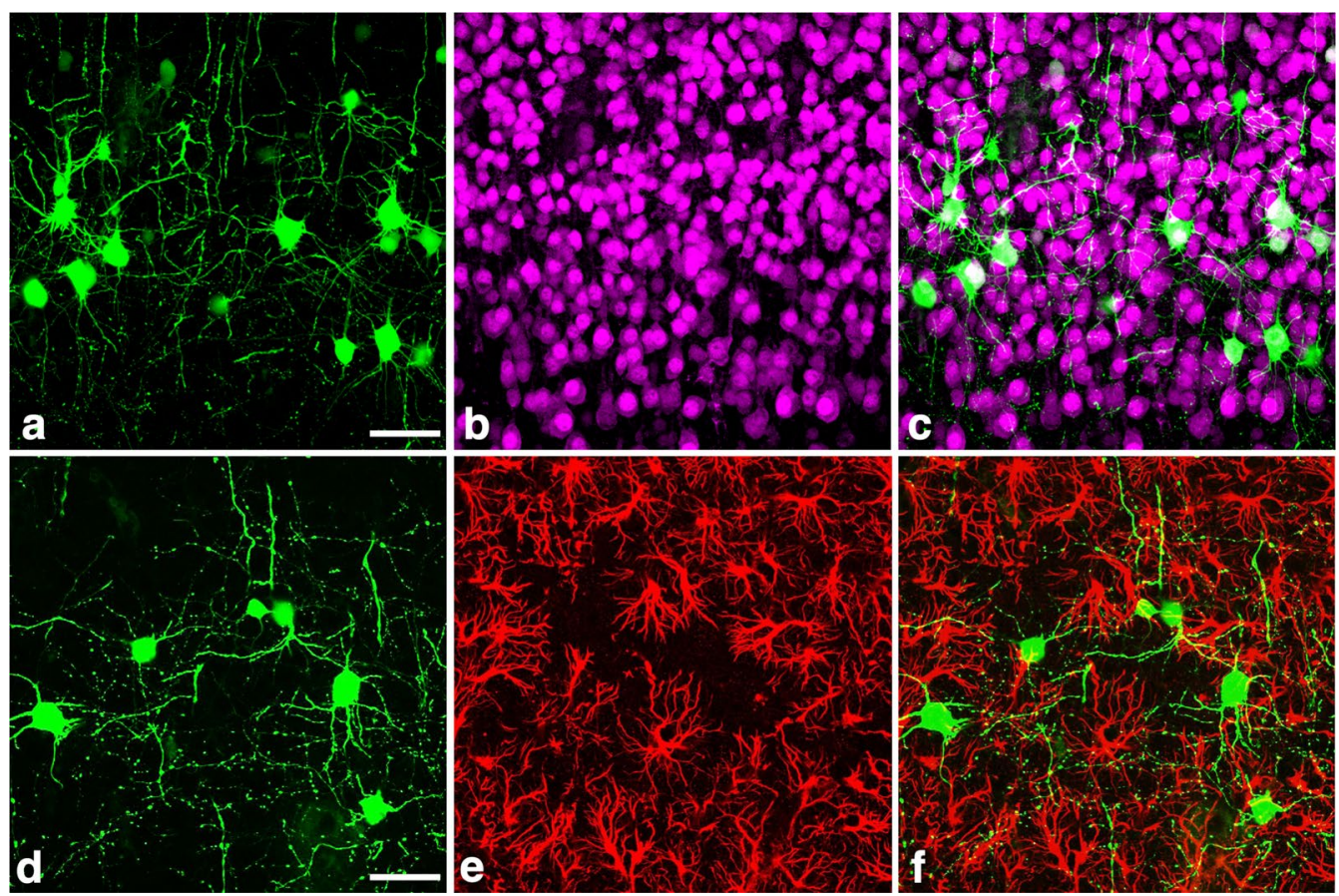

Fig. 8 The activation of MCMV e1-pro-1373 exclusively in neurons, but not in differentiated CX astrocytes during the second postnatal week. Fluorescence views of EGFP $(\mathbf{a}, \mathbf{d})$, immunofluorescence for NeuN (b) or GFAP $(\mathbf{e})$ and merged images of EGFP and each marker $(\mathbf{c}, \mathbf{f})$ in the CXs of neonatal mice infected with rMCMC1373 at 11 dpi are shown. a Almost all EGFP ${ }^{+}$cells demonstrate a morphology of the pyramidal neuron. $\mathbf{b}$ In the same field as $\mathbf{a}$, NeuN (purple) is expressed in the nuclei of CX neurons. c A merged image of $\mathbf{a}$ and $\mathbf{b}$. Nuclear areas of EGFP+ ${ }^{+}$CX neurons appear whitish because of the co-localization of EGFP and NeuN, indicating that e1-pro-1373 is distinctly activated in neurons. $\mathbf{d}$ Another fluorescence image of EGFP. $\mathbf{e}$ In the same field as d, GFAP (red) is expressed in the cytoplasm of differentiated astrocytes, a morphology of which is distinctly different from that of EGFP+-pyramidal neurons in $\mathbf{d}$. $\mathbf{f} A$ merged image of $\mathbf{d}$ and $\mathbf{e}$. EGFP is not accurately co-localized with GFAP, indicating that the activation of e1-pro-1373 does not occur in differentiated CX astrocytes. Scale bars: a-f $50 \mu \mathrm{m}$

It is possible that the deletion of the MCMV-M128 gene via the insertion of the e1-pro construct into the wild type MCMV genome causes rMCMVs to alter their viral nature, particularly in terms of pathogenesis. However, such a possibility is minimal for the following reasons. It has been reported that the deletion of the MCMV-M128 gene has no effect on viral growth in MEFs as well as on growth, latency, and pathogenesis in mice [11]. Furthermore, in this study, a comparison of rMCMVs with wild type MCMV revealed no significant differences in viral replication or E1 expression either in vitro or in vivo, suggesting that the recombination of the wild type virus has no effect on the pathogenesis or activation of e1-pro originally located in the viral genome.

During lytic infection, MCMV-E1-proteins, similarly to HCMV-E1-proteins, are essential for viral DNA replication, as they can bind DNA and accumulate in viral replication compartments within the host cell nuclei [1, 33, 45]. Eventually, the host cell dies after the production of viral progeny with rapid and exponential viral growth. This kind of infection is exactly observed in CMV infections of MEFs and NSPCs [28, 32, 37, 44]. In
CMV-infected embryonic NSPCs from the PV region, the disruption of their proliferation and differentiation causes serious and permanent sequelae such as microcephaly $[31,51]$. Furthermore, the activation of e1-pro by MCMV-IE3 (product of ie gene; M122-123), a homologue of HCMV-IE2, is critical for the expression of E1-proteins $[34,39]$. It is thought that IE3 can interact with $e 1$-pro and TATA binding protein (TBP) simultaneously to clamp the transcription factor IID (TFIID) complex onto e1-pro, which drives $e 1$ gene transcription $[1,33,39,45]$. Specific binding sites of MCMV-IE3 or HCMV-IE2 are known to exist between the transcriptional start site and nt -172 or nt -290 , respectively, within the CMV e1-pro sequences [4, 39, 47]. The present study consistently confirmed that the short e1-pro-448 including the IE3 binding site is sufficient to activate E1 expression and cause lytic infection in nonneuronal cells such as MEFs, NSPCs and perivascular macrophages in the developing brain. Most previous reports concerning CMV infection of the developing brain also demonstrated that lytic CMV infection 


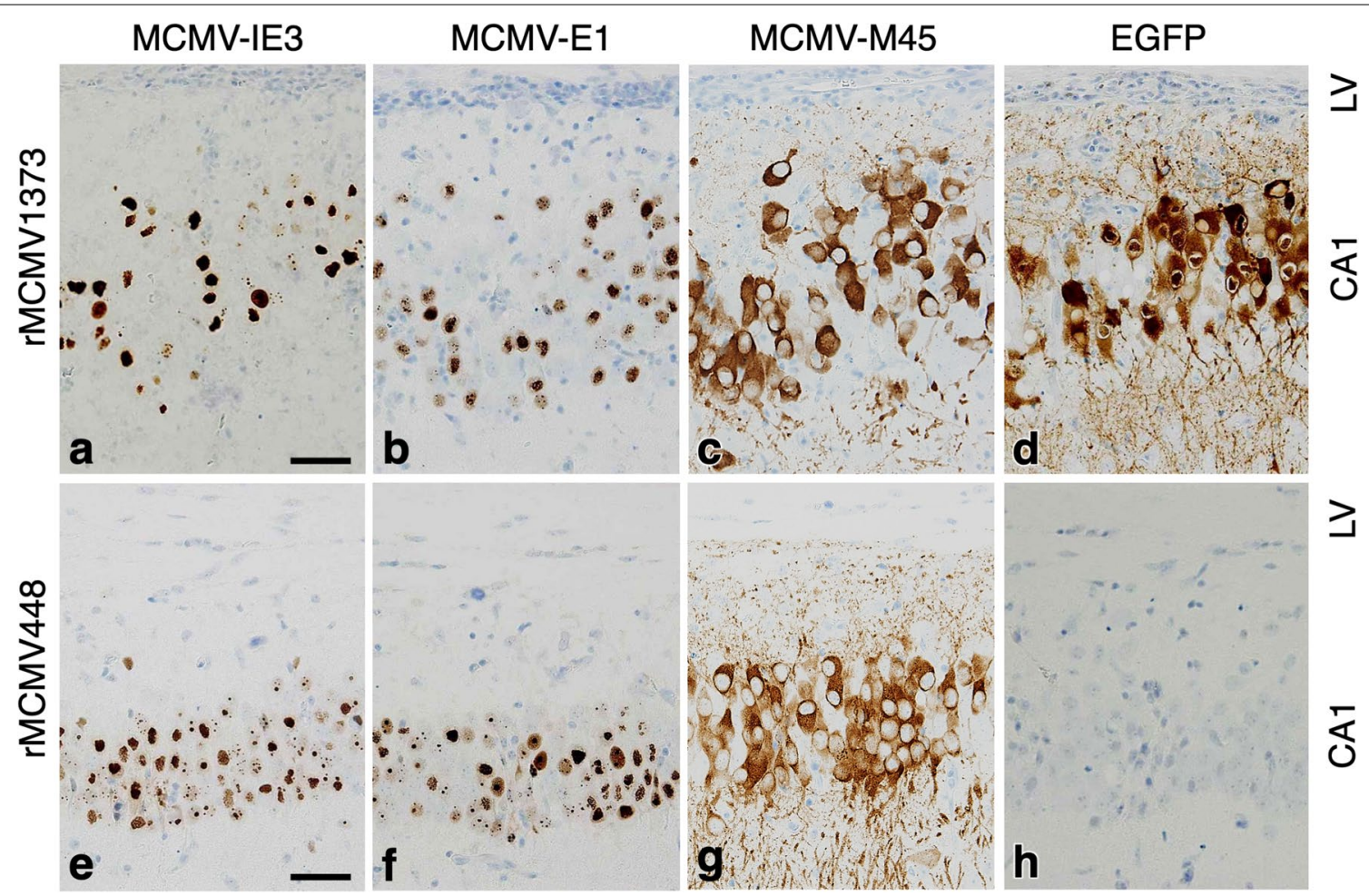

Fig. 9 Immunohistochemical detection of MCMV-IE3, -E1, -M45 and EGFP in the serial sections of the HP infected with rMCMV1373 (a-d) or -448 (e-h) at 11 dpi. a, e MCMV-IE3 (brown) is expressed in the nuclei of the hippocampal neurons infected with either rMCMV1373 (a) or rMCMV448 (e). b, f MCMV-E1 (brown) is expressed in the nuclei in a similar manner to IE3. c, g MCMV-M45 (brown) is also expressed in the cytoplasm of hippocampal neurons with a pyramidal morphology. $\mathbf{d}, \mathbf{h}$ EGFP (brown) was strongly expressed in the whole cell bodies of pyramidal neurons in the rMCMV1373-infected HP (d), but not expressed in the rMCMV448-infected HP (h). Nuclei are counterstained with hematoxylin. LV, lateral ventricle. Scale bars: $\mathbf{a}-\mathbf{h} 100 \mu \mathrm{m}$

occurred, particularly in the PV region either in animal models [13, 29, 31, 44] or human materials [51].

Unlike the lytic infection of non-neuronal cells, MCMV-infected neurons, either in primary neuronal cultures or postnatal brains, demonstrated a unique persistent infection. These neurons, accounting for $90 \%$ of MCMV-infected cells in primary neuronal cultures, showed very a low and flat viral titer of less than one thousandth of that in MCMV-infected MEFs, although these neurons adequately expressed E1 as observed in virus-infected MEFs. Similarly, in postnatal mice brains infected with MCMV, cerebral neurons of the HP and $\mathrm{CX}$ at $11 \mathrm{dpi}$ exclusively showed prolonged expression of $\mathrm{E} 1$, despite a marked reduction in viral titer in the brain and the disappearance of lytic infection in the PV region. Interestingly, the activation of the short e1-pro-448 in MCMV-infected neurons did not occur entirely in vitro or in vivo, though IE3 is properly expressed in these neurons and the long e1-pro-1373 was sufficiently activated. These results indicate that the short e1-pro-448 sequence alone is insufficient to drive the IE3-mediated activation of e1-pro in neurons or that it undergoes certain inhibition unlike in non-neuronal cells. Thus, the upstream sequence from nt -449 to -1373 in the long e1-pro-1373 sequence is supposed to work as an enhancer that is necessary to activate e1-pro, particularly in MCMV-infected neurons.

The transgenic mice carrying a long e1-pro, such as e1-pro-1373, demonstrated e1-pro activation specifically in the postnatal cerebral neurons without MCMV infection or activation via IE3-binding, suggesting that the long e1-pro including the upstream enhancer sequence on the host genome could be independently activated through a unique mechanism exclusive to these neurons [3]. Furthermore, because of the augmentation of e1-pro activation by MCMV infection in the cerebral neurons of the transgenic mice, the upstream enhancer would interact with neuron-specific factor(s) to support e1-pro activation via IE3 binding. Therefore, during actual MCMV infection the upstream enhancer sequence may be essential in driving the neuron-specific activation of e1-pro.

In the developing neurons it is possible that the activation of e1-pro at peaks during the postnatal period from around 1 to 2 weeks (the second postnatal week), 


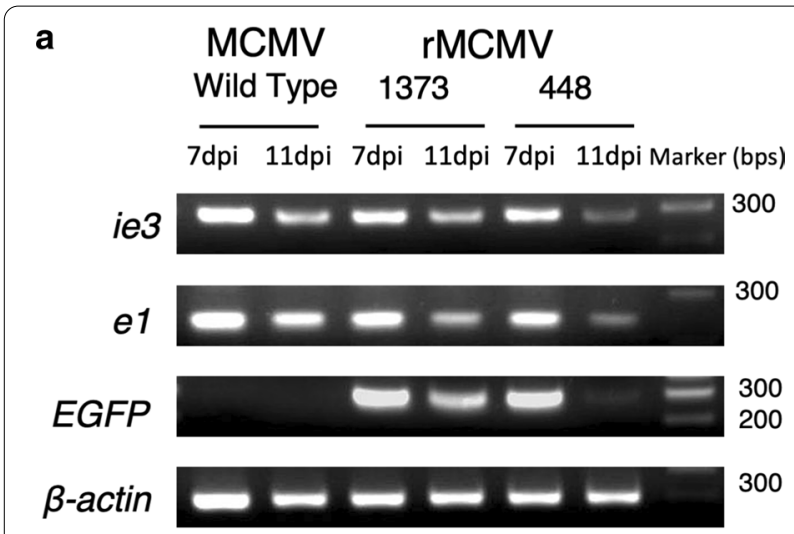

b
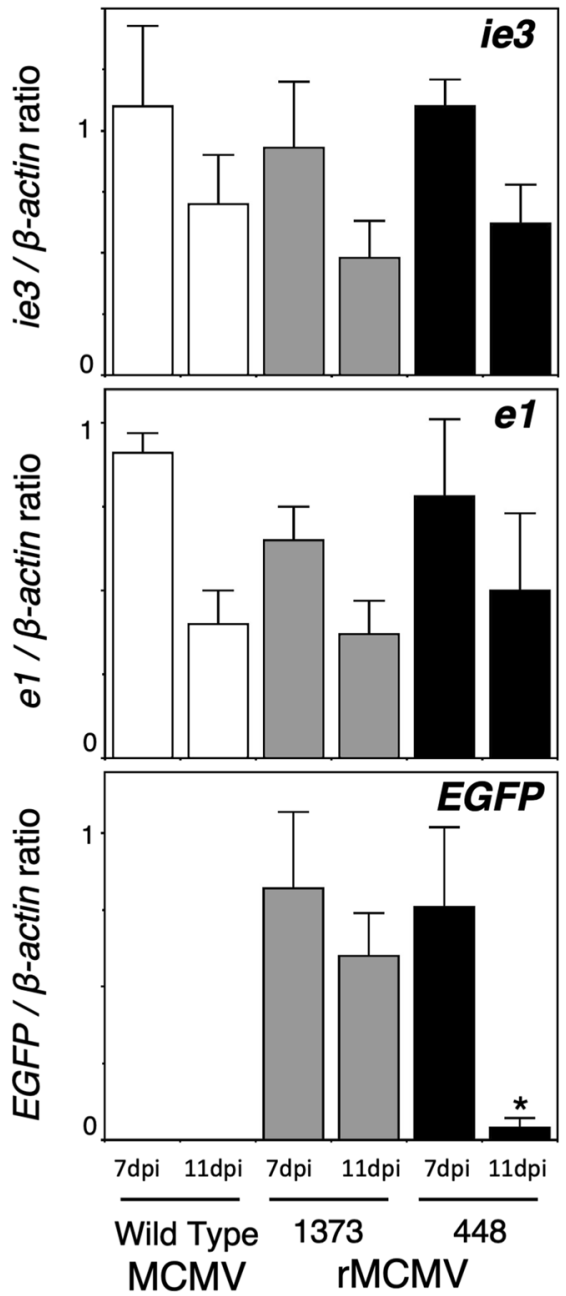

Fig. 10 RT-PCR analyses for the transcription of MCMV-IE3, MCMV-E1 and EGFP mRNA in the cerebrums infected with wild-type MCMV and rMCMVs at 7 and $11 \mathrm{dpi}$. The RT-PCR product of constitutively expressed $B$-actin was used as a control. a Representative data from three independent experiment are shown. $\mathbf{b}$ The ratio of the intensity of the RT-PCR signal of IE3, E1 or EGFP to that of ß-actin. Mean \pm SEM of 3 mouse cerebrums in each experimental group are shown (wild-type MCMV, white bar; rMCMV1373, gray bar; rMCMV448, black bar). ${ }^{*} p<0.01$ vs. corresponding rMCMV1373-infected cerebrum at 11 dpi by an unpaired 2-tailed Student's $t$-test according to the following studies as well as the present one. Previous reports concerning intrauterine MCMV infection demonstrated that immature neurons in the embryonic cerebrum during corticogenesis did not express MCMV-E1, despite NSPCs showing lytic infection [31, 44]. However, at P7 (13 dpi), MCMV-E1 was expressed in the cortical and hippocampal neurons [48]. Thereafter MCMV-E1 expression in neurons disappeared until postnatal 1 month [52]. Similarly, in postnatal MCMV infection, E1 was not expressed in the cerebral neurons during the early postnatal phase. Then, at P8, MCMV-E1 was observed to dramatically appear in the cerebral neurons in the present and previous studies [26, 29]. This unique expression of MCMV-E1 in the cerebral neurons was still maintained at P12 and thereafter gradually declined (data not shown). These findings suggest that in the immature neurons during the embryonic and early postnatal phase, MCMV-E1 may not be expressed due to the complete repression of e1-pro activity. Then, around the second postnatal week, this repression may be removed and, at the same time, e1-pro activated. It is supposed that the upstream enhancer sequence participates in the removal of this repression specifically in the developing neurons at this time.

During the second postnatal week in rodents which corresponds to the human gestational period from around 19 to 24 weeks [16], the cortical pyramidal neurons demonstrate rapid growth in overall dendrite length, more than doubling in a week $[30,43]$. Furthermore, the cerebrum extensively reorganizes gene expression for completing neuronal differentiation and promoting the processes of maturation such as synaptogenesis, neurite outgrowth and myelination $[36,50]$. It is possible that in MCMV-infected developing neurons these substantial transcriptional changes would also trigger the removal of the repression of e1-pro activation through the probable action of the upstream enhancer sequence. In addition, it is conceivable that MCMV proteins including E1, which are induced after the release of the repression, may adversely impact on the cellular functions of the developing cerebral neurons, resulting in the neurodevelopmental disorders. This concept seems to be supported by previous reports that CMV infection in the hippocampal neurons reduces the expression of the $\mathrm{N}$-methyl-D-aspartate (NMDA) subtype of glutamate receptors, which are essential for the plasticity of synapses and the learning $[18,26,60]$.

It has been reported that many neurotropic viruses cause persistent neuronal infection without cytopathicity [19, 38]. Although in MCMV-infected neurons the expression of viral antigens including E1 seems to persist until no longer than postnatal 1 month [52], it is expected that these neurons could survive with certain functional 
disturbances caused by MCMV infection, as described above, for the following reasons. First, MCMV-infected neurons both in vitro and in vivo preserved fine neuronal morphology without cytopathic effects, such as signs of lytic cell death observed in non-neuronal cells. In these neurons, the level of MCMV gene expression may be restricted so that lytic cell death with the production of infectious viral particles would hardly occur. Furthermore, these neurons are considered to resist cell death, such as excitotoxic cell death, induced by excess glutamate [27], because MCMV has several genes for anti-apoptosis and -necrosis proteins, including M45, as shown in this study $[9,27,57]$. Second, it is well-known that CMV has strategies for the evasion of innate immunity [20]. During MCMV infection of the neonatal brain, MCMV-infected cerebral neurons preferentially escaped the detection of NK cells and macrophages, and survived, while non-neuronal cells with lytic viral infection in the $\mathrm{PV}$ region were attacked by these innate immune cells and disappeared [29]. Interestingly, persistent HCMV infection in vitro was also demonstrated in human neurons differentiated from neonatal neural progenitor cells. These neurons survived with the preservation of neuronal morphology and displayed the persistent expression of viral antigens without cytopathic effects [32]. Therefore, these dysfunctional surviving neurons caused by CMV infection may be responsible for the subsequent neurodevelopmental disorders including psychiatric diseases.

In recent years, it has been reported that perinatal insults to the developing brain such as infections, inflammation or immunological disturbance appear to cause neuropsychiatric consequences in later life, such as autism spectrum disorders or schizophrenia $[2,6,23]$. In the case of HCMV infection, the linking of perinatal HCMV infection to schizophrenia has been controversial $[7,12]$, while Børglum et al. reported a significant relationship between maternal HCMV infection and some populations of schizophrenia patients [8]. However, until now there have been no human studies with direct evidence of HCMV infection in the cerebral neurons of patients with these neuropsychiatric diseases.

Hence, our finding of a unique neuron-specific MCMV infection in the postnatal stage of murine cerebral development may provide a clue to investigating the pathogenesis of neuropsychiatric diseases.

\section{Conclusions}

In this study we tried to clarify factors that determine the susceptibility of developing cerebral neurons to CMV infection. Based on an established mouse model of MCMV infection, we focused on the mechanism of promoter activation of an essential viral gene, MCMV-e1 gene, in developing cerebral neurons of neonatal mice. By means of the rMCMVs carrying constructs made up of different lengths of e1-pro connected with an EGFP reporter, the spaciotemporal activation of e1-pro during actual MCMV infection in vitro and in vivo were investigated. Consequently, we found that short e1-pro-448 is sufficient to activate E1 expression in non-neuronal cells, however, the upstream sequence from nt -449 to -1373 in long e1-pro-1373 is supposed to work as an enhancer necessary for the neuron-specific activation of e1-pro associated with a persistent infection, particularly around the second postnatal week. This unique activation of e1-pro in developing cerebral neurons may be an important factor in the neurodevelopmental disorders induced by congenital CMV infection.

\section{Abbreviations}

MCMV: Murine cytomegalovirus; HCMV: Human cytomegalovirus; e1: Early gene 1; E1: Early protein 1; ie3: Immediate-early gene 3; IE3: Immediate-early protein 3; e1-pro: e1-Promoter; EGFP: Enhanced green fluorescent protein; rMCMV: Recombinant MCMV; MEF: Mouse embryonic fibroblast; NSPC: Neural stem/progenitor cells; PV: Periventricular; HP: Hippocampus; CX: Cerebral cortex; MOI: Multiplicity of infection; PFU: Plaque forming unit; dpi: Days post-infection.

\section{Supplementary Information}

The online version contains supplementary material available at https://doi. org/10.1186/s40478-021-01139-0.

Additional file 1: Figure S1. The detailed construction, preparation method and verification of rMCMVs. a Construction of rMCMV448 and rMCMV1373. Map of the HindIII F, K, L and J fragments of the MCMV (Smith strain) genome. The arrangements of the original MCMV-e1-pro (position 161605 to 162977), M112/113 (e1) (position 1612978 to 165076), M122/123 (ie1/ie3) and M128 genes (position 186085 to 187296) in wild type MCMV are shown. During MCMV infection, IE3 protein, which is translated from the spliced transcript of the M122/123 gene, binds and trans-activates MCMV-e1-pro, causing E1-protein production. In this study, an e1-pro-EGFP cassette consisting of an e1-pro fragment (nt -1373 or -448 to +38 relative to the transcription start site) (black arrow), EGFP gene (gray arrow) and SV40-derived polyadenylation signal (short black box), was inserted into the position between the $5^{\prime}$ - (183081 to 184430) and $3^{\prime}$ - (187159 to 188573) flanking sequences (striped arrows) in the MCMV genome by homologous recombination. This recombination causes the deletion of the nt 2728 sequence including the greater part of the M128 gene (184431 to 187158). However, the M128 gene is completely dispensable for viral growth in cell cultures as well as for growth, latency, and pathogenesis in mice [11]. It is supposed that the deletion of the M128 gene has almost no effect on endogenous ie promoter activation. During the infection of recombinant viruses, the activation of the inserted e1-pro can be in situ detected as the expression of EGFP (in situ reporter assay in Fig. S1b). $\mathbf{b}$ A recomobinant virus was created by the co-transfection of MEFs with the genomic DNA of MCMV Smith strain and a recombinant DNA fragment of the e1-pro-EGFP cassette with the $5^{\prime}$-(position from 183078 to 184442 ) and $3^{\prime}$-(position from 187159 to 188573 ) flanking sequences using FuGENE 6 transfection reagent (Promega, \#E2691, Madison, WI). A transfer vector, which contained the flanking DNA fragment described above, was constructed based on the plasmid vector PEGFP-C1 (Gene accession number U55763, Clontech, Takara Bio USA). After the deletion of the HCMV enhancer/promoter sequence and multiple cloning sites from pEGFP-C1, the PCR-amplified e1-pro, 5'-, and $3^{\prime}$-flanking sequences were cloned into the Asel/Nhel, Asel and M/ul sites of PEGFP-C1, 
respectively. During the $P C R$ amplification of the flanking sequences, novel $\mathrm{Kpnl}$ sites were made at the start of the $5^{\prime}$ - and the end of the $3^{\prime}$-flanking sequences, so that a recombinant DNA fragment of the e1-proEGFP cassette with $5^{\prime}$ - and $3^{\prime}$-flanking sequences was readily prepared by Kpnl-digestion of the transfer vector. After the co-transfection of MEFs with viral genomic DNA and a recombinant DNA fragment as described above, the cells in a plaque with green fluorescence foci were picked up and transferred to an uninfected cell culture. This plaque purification was done at least three times. A virus preparation was considered pure when all foci resulting from limiting-dilution infections with this preparation displayed EGFP expression, indicating that no wild-type virus remained in the preparation. c Verification of rMCMV DNA. Viral genomic DNA was purified from virus-infected cells according to the Hirt method [Hirt B (1967) Selective extraction of polyoma DNA from infected mouse cell cultures. J Mol Biol 26:365-369. https://doi.org/10.1016/0022-2836(67)90307 -5]. Inserted sequences between the $3^{\prime}$-end of the $5^{\prime}$-flanking sequence and the $3^{\prime}$-end of the e1-pro-EGFP cassette were amplified by PCR using 5'-primer (GTC TTA TGG GTA GGG GGC TT) and 3'-primer (ATG AGT TTG GAC AAA CCA CAA C). To determine the size of the inserted e1-pro sequences, PCR products were digested by Nhel. On the other hand, the deletion of the M128 gene from the rMCMV DNA was examined by PCR amplification of a specific DNA sequence (186919 to 187125) in the M128 gene using 5'-primer (CTG AAG GAC AGG GTG TTC GT) and 3'-primer (AGC TAG CCT CCT CAC CTT CC). Inserted sequences between the $3^{\prime}$-end of the $5^{\prime}$-flanking sequence (5'-primer, arrow head) and the $3^{\prime}$-end of the e1-pro-EGFP cassette (3'-primer, arrow head) were specifically amplified as $2.4 \mathrm{kbp}$ and $1.5 \mathrm{kbp}$ signals from rMCMV-1373 and -448 DNA, respectively (lane 3 and 4), but not from the wild type MCMV DNA (lane 2). After the Nhel digestion of amplified sequences, $1.4 \mathrm{kbp}$ and $0.5 \mathrm{kbp}$ products of the expected promoter sequences were determined in rMCMV1373 and -448 DNA, respectively (lane 5 and 6 , arrow heads). On the other hand, the $207 \mathrm{bp}$ signal of the specific DNA sequence (186919 to 187125) in the M128 gene was identified in the wild type MCMV DNA (lane 8), but not in the rMCMV-1373 or -448 DNA (lane 9 and 10). These results indicate that the e1-pro-EGFP cassettes were accurately inserted into the expected position in the viral genomic DNA. Furthermore, the inserted e1-pro-EGFP cassettes amplified by PCR using the $5^{\prime}$ - and $3^{\prime}$-primers described above (lane 3 and 4 ) were sequenced and confirmed as appropriate inserts (Advanced Research Facilities and Services, Hamamatsu University School of Medicine).

\section{Acknowledgments}

The authors thank Ms. Motoe Kawashima, Ms. Hiromi Suzuki, Mr. Masaaki Kaneta (Department of Regenerative and Infectious Pathology, Hamamatsu University School of Medicine) and Mr. Kiyoshi Shibata (Advanced Research Facilities and Services, Hamamatsu University School of Medicine) for their excellent technical assistance.

\section{Authors' contributions}

IK and YT conceived and designed the study. IK, HK and YA contributed to the data acquisition. SB and IK designed and constructed recombinant viruses. IK, YT and TI wrote and reviewed the manuscript. All authors read and approved the final manuscript.

\section{Funding}

This work was supported in part by grants (\#20590396 and \#15K09709) from the Ministry of Education, Science, Culture and Technology, Japan.

\section{Availability of data and materials}

All data used and analyzed for the current study are available from the corresponding author on reasonable request.

\section{Declarations}

\section{Ethics approval and consent to participate}

All experimental procedures were performed in accordance with "Fundamental Guidelines for Proper Conduct of Animal Experiment and Related Activities in Academic Research Institutions under the jurisdiction of the Ministry of Education, Culture, Sports, Science and Technology (Ministry of Education,
Culture, Sports, Science and Technology, Notice No. 71, 2006)" and "Guidelines for Proper Conduct of Animal Experiments (The Guide; Science Council of Japan, 2006)", and were approved by the Animal Care Committee of Hamamatsu University School of Medicine (Reference number 2011057).

\section{Consent for publication}

All authors have given their consent for publication.

\section{Competing interests}

The authors declare that no competing interests exist.

\section{Author details}

${ }^{1}$ Department of Regenerative \& Infectious Pathology, Hamamatsu University School of Medicine, 1-20-1 Handayama, Higashi-Ku, Hamamatsu 431-3192, Japan. ${ }^{2}$ Department of Diagnostic Pathology, Toyohashi Municipal Hospital, 50 Hachiken-Nishi, Aotake-Cho, Toyohashi 441-8570, Japan. ${ }^{3}$ Department of Diagnostic Pathology, Hamamatsu University School of Medicine, 1-20-1 Handayama, Higashi-Ku, Hamamatsu 431-3192, Japan. ${ }^{4}$ Institute for NanoSuit Research, Hamamatsu University School of Medicine, 1-20-1 Handayama, Higashi-Ku, Hamamatsu 431-3192, Japan. ${ }^{5}$ Faculty of Health Science, Tokoha University, 1230 Miyakoda-Cho, Kita-Ku, Hamamatsu 431-2102, Japan.

Received: 10 January 2021 Accepted: 26 February 2021

Published online: 09 March 2021

\section{References}

1. Ahn JH, Jang WJ, Hayward GS (1999) The human cytomegalovirus IE2 and UL112-113 proteins accumulate in viral DNA replication compartments that initiate from the periphery of promyelocytic leukemia proteinassociated nuclear bodies (PODs or ND10). J Virol 73:10458-11041. https ://doi.org/10.1128/jvi.73.12.10458-10471.1999

2. Al-Haddad BJS, Jacobsson B, Chabra S, Modzelewska D, Olson EM, Bernier $R$ et al (2019) Long-term risk of neuropsychiatric disease after exposure to infection in utero. JAMA Psychiatry 76:594-602. https://doi.org/10.1001/ jamapsychiatry.2019.0029

3. Arai Y, Ishiwata M, Baba S, Kawasaki H, Kosugi I, Li R-Y et al (2003) Neuronspecific activation of murine cytomegalovirus early gene e1 promoter in transgenic mice. Am J Pathol 163:643-652. https://doi.org/10.1016/S0002 $-9440(10) 63691-7$

4. Arlt H, Lang D, Gebert S, Stamminger T (1994) Identification of binding sites for the 86-kilodalton IE2 protein of human cytomegalovirus within an IE2-responsive viral early promoter. J Virol 68:4117-4125. https://doi. org/10.1128/jvi.68.7.4117-4125.1994

5. Becroft DMO (1981) Prenatal cytomegalovirus infection: epidemiology, pathology, pathogenesis. In: Rosenberg HS, Bernstein J (eds) Perspectives in pediatric pathology. Madisson, New York, pp 203-241

6. Bilbo SD, Schwarz JM (2009) Early-life programming of later-life brain and behavior: A critical role for the immune system. Front Behav Neurosci 3:1-14. https://doi.org/10.3389/neuro.08.014.2009

7. Blomström GRM, Dalman C, Yolken RH, Karlsson H (2015) Influence of maternal infections on neonatal acute phase proteins and their interaction in the development of non-affective psychosis. Transl Psychiatry 5:1-7. https://doi.org/10.1038/tp.2014.142

8. Børglum AD, Demontis D, Grove J, Pallesen J, Hollegaard MV, Pedersen CB et al (2014) Genome-wide study of association and interaction with maternal cytomegalovirus infection suggests new schizophrenia loci. Mol Psychiatry 19:325-333. https://doi.org/10.1038/mp.2013.2

9. Brune W (2011) Inhibition of programmed cell death by cytomegaloviruses. Virus Res 157:144-150. https://doi.org/10.1016/j.virus res.2010.10.012

10. Bühler B, Keil GM, Weiland F, Koszinowski UH (1990) Characterization of the murine cytomegalovirus early transcription unit e1 that is induced by immediate-early proteins. J Virol 64:1907-1919. https://doi.org/10.1128/ jvi.64.5.1907-1919.1990

11. Cardin RD, Abenes GB, Stoddart CA, Mocarski ES (1995) Murine cytomegalovirus IE2, an activator of gene expression, is dispensable for growth and latency in mice. Virology 209:236-241. https://doi.org/10.1006/ viro.1995.1249 
12. Carter CJ (2009) Schizophrenia susceptibility genes directly implicated in the life cycles of pathogens: cytomegalovirus, influenza, herpes simplex, rubella, and toxoplasma gondii. Schizophr Bull 35:1163-1182. https://doi. org/10.1093/schbul/sbn054

13. Chang WLW, Tarantal AF, Zhou SS, Borowsky AD, Barry PA (2002) A recombinant rhesus cytomegalovirus expressing enhanced green fluorescent protein retains the wild-type phenotype and pathogenicity in fetal macaques. JVirol 76:9493-9504. https://doi.org/10.1128/ jvi.76.18.9493-9504.2002

14. Cheeran MCJ, Lokensgard JR, Schleiss MR (2009) Neuropathogenesis of congenital cytomegalovirus infection: disease mechanisms and prospects for intervention. Clin Microbiol Rev 22:99-126. https://doi. org/10.1128/CMR.00023-08

15. Cinque P, Marenzi R, Ceresa D (1997) Cytomegalovirus infections of the nervous system. Intervirology 40:85-97. https://doi.org/10.1159/00015 0536

16. Clancy B, Darlington RB, Finlay BL (2001) Translating developmental time across mammalian species. Neuroscience 105:7-17. https://doi. org/10.1016/S0306-4522(01)00171-3

17. Conboy TJ, Pass RF, Stagno S, Britt WJ, Alford CA, McFarland CE, Boll TJ (1986) Intellectual development in school-aged children with asymptomatic congenital cytomegalovirus infection. Pediatrics 77:801-806

18. D'Aiuto L, Di Maio R, Heath B, Raimondi G, Milosevic J, Watson AM et al (2012) Human induced pluripotent stem cell-derived models to investigate human cytomegalovirus infection in neural cells. PLOS ONE 7:1-12. https://doi.org/10.1371/journal.pone.0049700

19. De La Torre JC, Mallory M, Brot M, Gold L, Koob G, Oldstone MBA, Masliah E (1996) Viral persistence in neurons alters synaptic plasticity and cognitive functions without destruction of brain cells. Virology 220:508-515. https://doi.org/10.1006/viro.1996.0340

20. De Pelsmaeker S, Romero N, Vitale M, Favoreel HW (2018) Herpesvirus evasion of natural killer cells. JVirol 92:1-19. https://doi.org/10.1128/ jvi.02105-17

21. Ebihara K, Minamishima Y (1984) Protective effect of biological response modifiers on murine cytomegalovirus infection. J Virol 51:117-122. https ://doi.org/10.1128/jvi.51.1.117-122.1984

22. Fowler KB, Stagno S, Pass RF, Britt WJ, Boll TJ, Alford CA (1992) The Outcome of congenital cytomegalovirus infection in relation to maternal antibody status. N Engl J Med 326:663-667. https://doi.org/10.1056/ NEJM199203053261003

23. Hagberg H, Gressens P, Mallard C (2012) Inflammation during fetal and neonatal life: Implications for neurologic and neuropsychiatric disease in children and adults. Ann Neurol 71:444-457. https://doi.org/10.1002/ ana. 22620

24. Ishiwata M, Baba S, Kawashima M, Kosugi I, Kawasaki H, Kaneta M et al (2006) Differential expression of the immediate-early 2 and 3 proteins in developing mouse brains infected with murine cytomegalovirus. Arch Virol 151:2181-2196. https://doi.org/10.1007/s00705-006-0793-0

25. Kim J, Koo BK, Knoblich JA (2020) Human organoids: model systems for human biology and medicine. Nat Rev Mol Cell Biol 21:571-584. https:// doi.org/10.1038/s41580-020-0259-3

26. Kosugi I, Kawasaki H, Tsuchida T, Tsutsui Y (2005) Cytomegalovirus infection inhibits the expression of $\mathrm{N}$-methyl-D-aspartate receptors in the developing mouse hippocampus and primary neuronal cultures. Acta Neuropathol 109:475-482. https://doi.org/10.1007/s00401-005-0987-7

27. Kosugi I, Shinmura Y, Li RY, Aiba-Masago S, Baba S, Miura K, Tsutsui Y (1998) Murine cytomegalovirus induces apoptosis in non-infected cells of the developing mouse brain and blocks apoptosis in primary neuronal culture. Acta Neuropathol 96:239-247. https://doi.org/10.1007/s0040 10050890

28. Kosugi I, Shinmura Y, Kawasaki H, Arai Y, Li R-Y, Baba S, Tsutsui Y (2000) Cytomegalovirus infection of the central nervous system stem cells from mouse embryo: a model for developmental brain disorders induced by cytomegalovirus. Lab Investig 80:1373-1383. https://doi.org/10.1038/ labinvest.3780145

29. Kosugi I, Kawasaki H, Arai Y, Tsutsui Y (2002) Innate immune responses to cytomegalovirus infection in the developing mouse brain and their evasion by virus-infected neurons. Am J Pathol 161:919-928. https://doi. org/10.1016/S0002-9440(10)64252-6

30. Kroon T, van Hugte E, van Linge L, Mansvelder HD, Meredith RM (2019) Early postnatal development of pyramidal neurons across layers of the mouse medial prefrontal cortex. Sci Rep 9:1-16. https://doi.org/10.1038/ s41598-019-41661-9

31. Li RY, Tsutsui Y (2000) Growth retardation and microcephaly induced in mice by placental infection with murine cytomegalovirus. Teratology 62:79-85. https://doi.org/10.1002/1096-9926(200008)62:2\%3c79::AIDTERA3\%3e3.0.CO;2-S

32. Luo MH, Schwartz PH, Fortunato EA (2008) Neonatal neural progenitor cells and their neuronal and glial cell derivatives are fully permissive for human cytomegalovirus infection. J Virol 82:9994-10007. https://doi. org/10.1128/jvi.00943-08

33. Martínez FP, Cruz Cosme RS, Tang Q (2010) Murine cytomegalovirus major immediate-early protein 3 interacts with cellular and viral proteins in viral DNA replication compartments and is important for early gene activation. J Gen Virol 91:2664-2676. https://doi.org/10.1099/vir.0.02230 1-0

34. Messerle M, Bühler B, Keil GM, Koszinowski UH (1992) Structural organization, expression, and functional characterization of the murine cytomegalovirus immediate-early gene 3. J Virol 66:27-36. https://doi. org/10.1128/jvi.66.1.27-36.1992

35. Mocarski E, Courcelle C (2001) Cytomegaloviruses and their replication. In: Knipe DM, Howley PM, Griffin DE, Lamb RA, Martin MA, Roizman B, Straus SE (eds) Fields virology, 4th edn. Lippincott Williams \& Wilkins, Philadelphia, PA, pp 2629-2673

36. Mody M, Cao Y, Cui Z, Tay KY, Shyong A, Shimizu E et al (2001) Genomewide gene expression profiles of the developing mouse hippocampus. Proc Natl Acad Sci USA 98:8862-8867. https://doi.org/10.1073/ pnas. 141244998

37. Odeberg J, Wolmer N, Falci S, Westgren M, Seiger Å, Söderberg-Nauclér C (2006) Human cytomegalovirus inhibits neuronal differentiation and induces apoptosis in human neural precursor cells. J Virol 80:8929-8939. https://doi.org/10.1128/jvi.00676-06

38. Oldstone MBA (1989) Viruses can cause disease in the absence of morphological evidence of cell injury: implication for uncovering new diseases in the future. J Infect Dis 159:384-389. https://doi.org/10.1093/ infdis/159.3.384

39. Perez KJ, Martinez FP, Cosme-Cruz R, Perez-Crespo NM, Tang Q (2013) A short cis-acting motif in the M112-113 promoter region is essential for IE3 to activate M112-113 gene expression and is important for murine cytomegalovirus replication. JVirol 87:2639-2647. https://doi.org/10.1128/ jvi.03171-12

40. Perlman JM, Argyle C (1992) Lethal cytomegalovirus infection in preterm infants: clinical, radiological, and neuropathological findings. Ann Neurol 31:64-68. https://doi.org/10.1002/ana.410310112

41. Rawlinson WD, Farrell HE, Barrell BG (1996) Analysis of the complete DNA sequence of murine cytomegalovirus. J Virol 70:8833-8849. https://doi. org/10.1128/jvi.70.12.8833-8849.1996

42. Reddehase MJ (2002) Antigens and immunoevasins: opponents in cytomegalovirus immune surveillance. Nat Rev Immunol 2:831-844. https:// doi.org/10.1038/nri932

43. Romand S, Wang Y, Toledo-Rodriguez M, Markram H (2011) Morphological development of thick-tufted layer $\vee$ pyramidal cells in the rat somatosensory cortex. Front Neuroanat 5:1-27. https://doi.org/10.3389/ fnana.2011.00005

44. Sakao-Suzuki M, Kawasaki H, Meguro S, Iwashita T, Tsutsui Y, Inoue N, Kosugi I (2014) Aberrant fetal macrophage/microglial reactions to cytomegalovirus infection. Ann Clin Transl Neurol 1:570-588. https://doi. org/10.1002/acn3.88

45. Sarisky RT, Hayward GS (1996) Evidence that the UL84 gene product of human cytomegalovirus is essential for promoting oriLyt-dependent DNA replication and formation of replication compartments in cotransfection assays. J Virol 70:7398-7413. https://doi.org/10.1128/ jvi.70.11.7398-7413.1996

46. SchommartzT, Loroch S, Alawi M, Grundhoff A, Sickmann A, Brune W (2016) Functional dissection of an alternatively spliced herpesvirus gene by splice site mutagenesis. J Virol 90:4626-4636. https://doi.org/10.1128/ jvi.02987-15

47. Schwartz R, Sommer MH, Scully A, Spector DH (1994) Site-specific binding of the human cytomegalovirus IE2 86 -kilodalton protein to an early gene promoter. JVirol 68:5613-5622. https://doi.org/10.1128/ jvi.68.9.5613-5622.1994 
48. Shinmura Y, Aiba-Masago S, Kosugi I, Li RY, Baba S, Tsutsui Y (1997) Differential expression of the immediate-early and early antigens in neuronal and glial cells of developing mouse brains infected with murine cytomegalovirus. Am J Pathol 151:1331-1340

49. Slavuljica I, Kveštak D, Csaba Huszthy P, Kosmac K, Britt WJ, Jonjić S (2015) Immunobiology of congenital cytomegalovirus infection of the central nervous system - the murine cytomegalovirus model. Cell Mol Immunol 12:180-191. https://doi.org/10.1038/cmi.2014.51

50. Stead JDH, Neal C, Meng F, Wang Y, Evans S, Vazquez DM, Akil H (2006) Transcriptional profiling of the developing rat brain reveals that the most dramatic regional differentiation in gene expression occurs postpartum. J Neurosci 26:345-353. https://doi.org/10.1523/JNEUROSCI.2755-05.2006

51. Teissier N, Fallet-Bianco C, Delezoide AL, Laquerrière A, Marcorelles $P$, Khung-Savatovsky S et al (2014) Cytomegalovirus-induced brain malformations in fetuses. J Neuropathol Exp Neurol 73:143-158. https://doi. org/10.1097/NEN.0000000000000038

52. Tsutsui Y, Kashiwai A, Kawamura N, Aiba-Masago S, Kosugi I (1995) Prolonged infection of mouse brain neurons with murine cytomegalovirus after pre- and perinatal infection. Arch Virol. https://doi.org/10.1007/ BF01384337

53. Tsutsui Y, Kashiwai A, Kawamura N, Nagahama M, Mizutani A, Naruse I (1989) Susceptibility of brain cells to murine cytomegalovirus infection in the developing mouse brain. Acta Neuropathol 79:262-270. https://doi. org/10.1007/BF00294660

54. Tsutsui Y, Naruse I (1987) Murine cytomegalovirus infection of cultured mouse embryos. Am J Pathol 127:262-270

55. Tsutsui Y (2009) Effects of cytomegalovirus infection on embryogenesis and brain development. Congenit Anom (Kyoto) 49:47-55. https://doi. org/10.1111/j.1741-4520.2009.00222.x

56. Tsutsui Y, Kosugi I, Kawasaki H (2005) Neuropathogenesis in cytomegalovirus infection: indication of the mechanisms using mouse models. Rev Med Virol 15:327-345. https://doi.org/10.1002/rmv.475
57. Upton JW, Kaiser WJ, Mocarski ES (2010) Virus inhibition of RIP3-dependent necrosis. Cell Host Microbe 7:302-313. https://doi.org/10.1016/j. chom.2010.03.006

58. van Den Pol AN, Mocarski E, Saederup N, Vieira J, Meier TJ (1999) Cytomegalovirus cell tropism, replication, and gene transfer in brain. J Neurosci 19:10948-10965. https://doi.org/10.1523/jneurosci.19-24-10948 .1999

59. van den Pol AN (2006) Viral infections in the developing and mature brain. Trends Neurosci 29:398-406. https://doi.org/10.1016/j. tins.2006.06.002

60. Wang Z, Qian D, Zhu W, Hu M, Qin Z, Zhang X et al (2018) Cx43 and NMDA receptors changes in UL122 genetically modified mice hippocampus: a mechanism for spatial memory impairment. Int J Clin Exp Pathol 11:129-137

61. Wentworth BB, French $L$ (1970) Plaque assay of cytomegalovirus strains of human origin. Proc Soc Exp Biol Med 135:253-258. https://doi. org/10.3181/00379727-135-35031

62. Workman AD, Charvet CJ, Clancy B, Darlington RB, Finlay BL (2013) Modeling transformations of neurodevelopmental sequences across mammalian species. J Neurosci 33:7368-7383. https://doi.org/10.1523/ JNEUROSCI.5746-12.2013

63. Wright DA, Spector DH (1989) Posttranscriptional regulation of a class of human cytomegalovirus phosphoproteins encoded by an early transcription unit. JVirol 63:3117-3127. https://doi.org/10.1128/ jvi.63.7.3117-3127.1989

\section{Publisher's Note}

Springer Nature remains neutral with regard to jurisdictional claims in published maps and institutional affiliations.
Ready to submit your research? Choose BMC and benefit from:

- fast, convenient online submission

- thorough peer review by experienced researchers in your field

- rapid publication on acceptance

- support for research data, including large and complex data types

- gold Open Access which fosters wider collaboration and increased citations

- maximum visibility for your research: over $100 \mathrm{M}$ website views per year

At BMC, research is always in progress.

Learn more biomedcentral.com/submissions 